\title{
TU/e EmonONEN

\section{Employing cold bonded pelletization to produce lightweight aggregates from incineration fine bottom ash}

\section{Citation for published version (APA):}

Tang, P., Florea, M. V. A., \& Brouwers, H. J. H. (2017). Employing cold bonded pelletization to produce lightweight aggregates from incineration fine bottom ash. Journal of Cleaner Production, 165, 1371-1384. https://doi.org/10.1016/j.jclepro.2017.07.234

\section{Document license: \\ TAVERNE}

DOI:

10.1016/j.jclepro.2017.07.234

\section{Document status and date:}

Published: 01/11/2017

\section{Document Version:}

Publisher's PDF, also known as Version of Record (includes final page, issue and volume numbers)

\section{Please check the document version of this publication:}

- A submitted manuscript is the version of the article upon submission and before peer-review. There can be important differences between the submitted version and the official published version of record. People interested in the research are advised to contact the author for the final version of the publication, or visit the $\mathrm{DOI}$ to the publisher's website.

- The final author version and the galley proof are versions of the publication after peer review.

- The final published version features the final layout of the paper including the volume, issue and page numbers.

Link to publication

\section{General rights}

Copyright and moral rights for the publications made accessible in the public portal are retained by the authors and/or other copyright owners and it is a condition of accessing publications that users recognise and abide by the legal requirements associated with these rights.

- Users may download and print one copy of any publication from the public portal for the purpose of private study or research.

- You may not further distribute the material or use it for any profit-making activity or commercial gain

- You may freely distribute the URL identifying the publication in the public portal.

If the publication is distributed under the terms of Article 25fa of the Dutch Copyright Act, indicated by the "Taverne" license above, please follow below link for the End User Agreement:

www.tue.nl/taverne

Take down policy

If you believe that this document breaches copyright please contact us at:

openaccess@tue.nl

providing details and we will investigate your claim. 


\title{
Employing cold bonded pelletization to produce lightweight aggregates from incineration fine bottom ash
}

\author{
P. Tang a, b, *, M.V.A. Florea ${ }^{\text {a }}$, H.J.H. Brouwers ${ }^{\mathrm{a}}$ \\ a Department of the Built Environment, Eindhoven University of Technology, 5612AP Eindhoven, The Netherlands \\ ${ }^{\mathrm{b}}$ Department of Civil and Environmental Engineering, The Hong Kong Polytechnic University, Hung Hom, Kowloon, Hong Kong
}

\section{A R T I C L E I N F O}

Article history:

Received 20 February 2017

Received in revised form

18 July 2017

Accepted 29 July 2017

Available online 1 August 2017

\section{Keywords:}

Bottom ash fine particles

Recycle

Reuse

Cold bonded pelletization

Lightweight aggregate

Concrete

\begin{abstract}
A B S T R A C T
Municipal solid waste incineration (MSWI) bottom ash fine particles $(0-2 \mathrm{~mm}, \mathrm{BAF})$ are a potential building material, but their possible environmental risk and poor physical properties hinder their application scale. In this study, the cold bonded pelletizing technique is applied to produce artificial lightweight aggregates using BAF and other industrial waste powders, as a way of recycling BAF mainly. The properties of the produced aggregates are determined and compared with other artificial aggregates. Moreover, the growth mechanism of the pellet with BAF and the role of BAF on pellet strength are addressed. The leaching properties of this aggregate are evaluated according to the environmental legislation. In addition, this aggregate is used as natural aggregate replacement in concrete to investigate its influence on concrete properties.
\end{abstract}

() 2017 Elsevier Ltd. All rights reserved.

\section{Introduction}

Recycling and reuse of solid waste from the industrial or construction field are significant and crucial nowadays; in consideration to the environment, plenty of research has been done on different types of solid wastes (Xuan et al., 2016a, 2016b; Zhang, 2013). Municipal solid waste incineration bottom ash (MSWIBA) is the main solid residue in waste-to-energy plants, which accounts for around $80 \%-90 \%$ of the total by-products; its coarse fraction (above 2 or $4 \mathrm{~mm}$ ) generally needs cleaning, considering its environmental impact, and then reused as aggregate in concrete (Keulen et al., 2015). However, its fine fraction (such as under $2 \mathrm{~mm}$ ) (BAF), which have the potential to be used as sand substitute in mortar or concrete (Al-Rawas et al., 2005; Li et al., 2012), contains relatively high amount of heavy metals (such as $\mathrm{Cu}, \mathrm{Sb}$, Mo, etc.) and salts (such as chlorides, sulphates, etc.), the leaching concentration of which exceed the limit value according to relevant environmental legislation (Tang et al., 2015; Soil Quality Decree, 2008). According to the Dutch legislation (Soil Quality Decree, 2008), the BAF without any treatment can only be used when the

\footnotetext{
* Corresponding author. Department of the Built Environment, Eindhoven University of Technology, 5612AP Eindhoven, The Netherlands.

E-mail address: p.tang@tue.nl (P. Tang).
}

material is isolated and monitored during the application period. Moreover, it is reported that the BAF contains metals which can lead to cracks when the BAF is used in mortar or concrete, and then reduce the strength and decrease the durability of the concrete (Tang et al., 2015; Müller and Rübner, 2006). The BAF can also end up in landfills (Bosmans et al., 2013); however, due to the decreasing available space and increasing cost for landfilling, this is not a preferable option and will not be allowed by Dutch legislation in the future.

In order to improve the properties of the BAF and eventually apply it as a usable/valuable material instead of treating it only as a waste, series of treatments are introduced, such as separation (Tang et al., 2016), carbonation (Meima et al., 2002), washing (Cossu et al., 2012), stabilization/solidification (Luna Galiano et al., 2011), etc. Nevertheless, the efficiency of the treatments on the BAF is limited compared with the coarse fraction of BA. For instance, due to the small particle size, the recovery rate of metals by the eddy currency separator is very low (Rahman and Bakker, 2013). Washing of BAF can reduce the leaching of salts significantly (Colangelo et al., 2012); however, a large amount of waste liquid will be generated, causing further problems. Weathering and carbonation could improve the leaching properties of the BAF under specific controlled conditions during the process (Santos et al., 2013), but the treated BAF is a porous material, with a low crushing strength, which may limit its application scale (can only be used in low 
quality concrete). Regarding stabilization/solidification, it is well known that cementitious materials have an excellent capacity to immobilize waste materials (Brouwers et al., 2007; Zhang et al., 2013; Voglar and Leštan, 2011), but the use of binders increases the treatment costs. So far, the recycling and reuse of MSWI BAF remains an issue to be solved in practise.

Nowadays, the cold bonded pelletizing technique is widely used to recycle industrial waste powders for producing artificial aggregates for application in concrete, and the raw materials (powder level) used are extended to various waste powders in recent years, such as iron ore fines (Dutta et al., 1997a), coal fly ash (Gesoğlu et al., 2007; Ferone et al., 2013) and bottom ash (Geetha and Ramamurthy, 2010a), granulated blast furnace slag (Gesoğlu et al., 2012), quarry dust (Thomas and Harilal, 2015), etc. The widespread research on the production of artificial aggregates using waste powders through cold bonded technique proposes a positive view on the investigation of producing artificial aggregate using BAF, which is rarely studied. This could be a method for the integral purposes of immobilizing the contaminants of BAF by cementitious materials, producing an artificial aggregate which can be used in concrete, and in this way transfer BAF from waste to value.

Regarding the recycling of industrial waste powdered materials by the cold bonded pelletizing technique, there are several aspects which have been investigated from literature (Geetha and Ramamurthy, 2010a; Gesoğlu et al., 2004, 2007, 2012, 2014; Thomas and Harilal, 2015; Dutta et al., 1992; Cioffi et al., 2011; Geetha and Ramamurthy, 2013; Bui et al., 2012; Colangelo et al., 2015; Manikandan and Ramamurthy, 2008; Dutta et al., 1997b; Baykal and Doven, 2000; Güneyisi et al., 2015a) and need to be considered for the design of pelletization, as listed in below:

- Types of waste powders to be recycled as raw materials for pelletization

The most used solid waste is coal fly ash, which accounts for over $50 \%$ of the total solids used for pelletization. In most study, cold bonded pelletization is treated as an efficient method to manage the coal fly ash (Thomas and Harilal, 2015; Colangelo et al., 2015). However, among all these recycled solid materials, the particle sizes of these materials are rather small $(<125 \mu \mathrm{m})$ compared to corresponding pellets they produced $(>4 \mathrm{~mm})$. The use of relatively bigger particles $(>125 \mu \mathrm{m})$ rather than only powders has rarely been reported. Moreover, the inherent characteristics of the raw materials have a significant influence on the properties of the produced lightweight aggregates.

\section{- Binder/activator}

To guarantee the strength of the produced lightweight aggregates, a certain amount of ordinary Portland cement is added, which normally accounts for $5-10 \%$ of the total solid mass (Dutta et al., 1997b; Gesoğlu et al., 2014; Gesoğlu et al., 2004). Another binder system is an alkali-activated binder (geopolymer), which consists of chemical activator and slag or fly ash (Geetha and Ramamurthy, 2013; Bui et al., 2012). Using this binder system for pelletization, the chemical activator in liquid form is generally sprayed on the powder as gluing agent instead of water, to promote the formation of granulates at the very early age of pelletization and later activate the slag or fly ash to provide strength to the pellets.

\section{- Additives}

There is research which shows that the addition of $\mathrm{CaO}$ or $\mathrm{Ca}(\mathrm{OH})_{2}$ contributes positively to the pelletization efficiency and the strength of the produced pellets (Geetha and Ramamurthy, 2010a; Cioffi et al., 2011). Ground-granulated blast-furnace slag (GGBS) from the steel industry and rice husk ash (RHA) from the combustion of rice husk were also used to improve the properties of the lightweight aggregates due to their contribution to cement hydration, or their own chemical activation (Bui et al., 2012).

\section{- Curing methods}

Several curing methods were applied in others' studies, including water curing, moisture curing, steam curing at different temperatures, autoclave curing, etc. (Manikandan and Ramamurthy, 2008). In most of the studies, moisture curing is performed by sealing the freshly produced aggregated in bags or buckets until testing date, this is also possible in large scale production. The other three types of curing can promote the strength development of the aggregates; however, it depends on the properties of the raw materials and the available conditions in practice.

\section{- Pelletizing parameters}

The pelletizing parameters include the diameter of the pan, its angle and speed, and the feeding speed of raw materials. The effect of the pelletizing parameters on the properties of the pellets depends on the pelletizer used and the other procedure parameters. The disc pelletizer used in literature had a diameter between 40 and $80 \mathrm{~cm}$, and the rotating angle and speed were $45-55^{\circ}$ and 35-55 rpm, respectively.

\subsection{Integral recycling of BAF and other industrial solid wastes by cold bonded pelletization in this study}

Considering the recycling of BAF in this study using the cold bonded pelletizing technique, the above-mentioned parameters need to be considered and determined. Due to the fact that BAF has a particle size between 0 and $2 \mathrm{~mm}$, it might be necessary to add other powdered materials to make sure there are enough fines to fill the space between bigger particles and then to glue all the particles together in a spherical shape when water is added. The powdered materials chosen are expected: 1) to act as filler to condense the microstructure of pellets which is significantly affect the pellet properties, and to have a good compatibility with other materials during pelletizing process; 2 ) to have pozzolanic or hydraulic characteristics which will contribute to the binder hydration, and eventually enhance the pellet properties; 3 ) the use of these chosen powdered materials can be eco- and environmental friendly, such as using wastes from industrial fields. In this way, the recycling of BAF by pelletizing technique is further valorised.

In the present study, except BAF, the chosen powdered materials are coal fly ash (FA), paper sludge ash (PSA) and washing aggregates sludge (WAS). In literature, the pelletization of FA to produce cold bonded aggregates has been widely studied and the technique is improved from both the mechanical and economic points of view (Gesoğlu et al., 2014; Baykal and Döven, 2000). Secondly, it is reported that FA could be used as filler, additive, or pozzolanic material in concrete, having a positive influence (Berryman et al., 2005). Hence, coal fly ash (FA) is chosen as one of the powder ingredients in this study. According to research (Cioffi et al., 2011; Geetha and Ramamurthy, 2010b), the addition of $\mathrm{Ca}(\mathrm{OH})_{2}$ or lime can increase the pelletizing efficiency, and improve the hydration of the binder, which improves the pellet properties indirectly. It is known from literature that paper sludge ash (PSA) is a solid waste from the paper recycling industry, which mainly contains free lime and calcite. It could be used as a hydraulic binder (Wong et al., 2015; Bin Mohd Sani et al., 2011), or raw material for eco-cement (Yen et al., 2011) for concrete. Therefore, the PSA which is available in 
the Netherlands is recycled and reused as a powder ingredient in this study from both the technical and economic points of view. To obtain the granulate during the pelletizing, particularly during the early stage, the moisture content and the plasticity of the raw materials are very important. Washing aggregate sludge (WAS) is a water-solids mixture (most of the solid particles are under $63 \mu \mathrm{m}$ ) collected from the aggregate washing plant, which needs to be settled in the clarifier before further use or deposit. This procedure is time consuming and not economically friendly. In other studies, this sludge is used to produce artificial aggregate by sintering (González-Corrochano et al., 2009; Volland and Brötz, 2015). The sludge normally contains $45 \%-55 \%$ liquid, which need to be drained out in normal treatment procedure; however, when being used for pelletization, the sludge mixture could be directly used without any other treatment (settling or draining). This is due to the fact that firstly the dried sludge is generally agglomerated and needs to be crushed or milled before use; secondly, during the pelletizing of raw material in this study, a certain amount of water is needed. Hence, the utilization of washing aggregate sludge (WAS) as one ingredient in pelletizing is a more cost-effective way to recycle it, which can avoid the pre-treatment of the sludge and decrease the consuming of water during the pelletizing process. In this way, the waste materials are directly used as raw resources for new products without additional treatments, which combine the reduction, recycle and reuse of the waste materials at the same time.

Therefore, in our current research, the MSWI BAF is one of the main solid wastes which need to be reused or recycled soon instead of being disposed in landfills according to the circular development plan in the Netherlands (Green deal, 2012). Meanwhile, FA, PSA, and WAS are chosen as raw materials to produce the lightweight aggregates, those materials are also solid wastes which need to be solved in consideration of environmental and economic aspects.

Hence, the main purpose is to investigate the potential of recycling the MSWI fine bottom ash $(0-2 \mathrm{~mm})$ through the pelletizing technique; meanwhile, the other industrial waste powders are also recycled in this way as powder ingredients due to their potential benefits on the pellet production. The possibility of recycling these solid wastes together using the pelletizing technique needs to be investigated firstly. The properties (such as density, pellet strength, crushing resistance, water absorption, etc.) of the artificial aggregate produced are evaluated. The leaching properties of the BAF and the aggregate are determined and compared with the legislation. The practical application of this artificial aggregate in concrete is also studied.

\section{Materials and methods}

\subsection{Raw materials and characterization}

The MSWIBA used in this study is collected from the waste-toenergy plant in Moerdijk (the Netherlands) which is in operation since 1997, and has an annual processing capacity of approximately one million ton of waste. The received municipal solid waste is mixed and directly incinerated at an average temperature of 950-1100 ${ }^{\circ} \mathrm{C}$, followed by water quenching. Then the ferrous and non-ferrous metals are recycled from the wet bottom ash in the plant. The wet bottom ash fine particles fraction $(0-2 \mathrm{~mm})$ is selected for the investigation in this study. These bottom ash fine particles (BAF) were obtained by sieving and sealed in a bag before use to avoid the variation of moisture content (around $1000 \mathrm{~kg}$ was collected and stored at once to reduce sample variety). Three other industrial powder wastes, which are facing similar reuse/recycling issues as BAF in the Netherlands as mentioned before, were also used in this study. These powders are coal fly ash (FA) from a Dutch power plant, paper sludge ash (PSA) from a Dutch paper recycling company, and washing aggregate sludge (WAS) from a gravel washing factory (Smals, the Netherlands). An Ordinary Portland Cement (OPC) CEM I $42.5 \mathrm{~N}$ (ENCI, the Netherlands) is used as binder.

The chemical compositions of the used materials are determined by X-ray fluorescence (XRF) and the X-ray diffraction (XRD, Cu tube, $40 \mathrm{kV}, 30 \mathrm{~mA}, 3-75^{\circ}, 0.02^{\circ} / \mathrm{step}, 0.2^{\circ} / \mathrm{min}$ ) is used to detect the crystalline phases present in the materials. Laser diffraction (Mastersizer 2000 Malvern) is employed to determine the particle size distributions (PSDs) of the powder materials, and the PSD of the particle aggregates is measured following the standard EN 9332, (1995). A helium pycnometer (AccuPyc II 1340) is used to measure the specific densities.

Table 1 shows the chemical compositions of the raw materials. It can be seen that $\mathrm{BAF}$ has high amounts of $\mathrm{SiO}_{2}$ and $\mathrm{Fe}_{2} \mathrm{O}_{3}$, and a low amount of $\mathrm{CaO}$; paper sludge ash (PSA) contains a quite high amount of $\mathrm{CaO}$ and a lower amount of $\mathrm{SiO}_{2}$. Combustion fly ash (FA) has high amounts of $\mathrm{SiO}_{2}$ and $\mathrm{Al}_{2} \mathrm{O}_{3}$, and a low amount of $\mathrm{CaO}$. Washing aggregate sludge (WAS) is mainly composed of $\mathrm{SiO}_{2}$ and $\mathrm{Al}_{2} \mathrm{O}_{3}$. It is also shown that BAF, PSA and WAS have very similar specific densities, intermediate between OPC and FA. The particle size distribution of the powders (OPC, WAS, PSA, FA) used are very similar, as shown in Fig. 1. Fig. 2 shows that the main crystalline phases in BAF are quartz, anhydrite, calcite and hematite. PSA mainly consists of calcite, calcium hydroxide, a small amount of quartz. The main crystalline phase in WAS is quartz, and FA contains quartz and calcite as well.

Isothermal calorimeter (eight-channel TAM Air, Thermometric) is employed to investigate the hydration development of the blended binders. The influence of the PSA and FA on the cement hydration are studied by replacing the cement by different proportions, respectively. The interaction between PSA, FA and cement is studied as well, based on which the proportions of PSA and FA for the pelletization are determined.

\subsection{Cold bonded lightweight aggregate manufacture and characterization}

\section{- Pelletization}

As stated before, the size of the disc pelletizer and parameters during the pelletization used in the literature varies, hence, the chosen pelletizing parameters are determined based on the information from literature and the practical experience acquired

Table 1

The chemical compositions and specific density of the raw materials.

\begin{tabular}{llllll}
\hline Composition [\% wt.] & CEM I $42.5 \mathrm{~N}$ & BAF & PSA & FA & WAS \\
\hline $\mathrm{CaO}$ & 67.9 & 18.6 & 54.9 & 6.2 & 1.5 \\
$\mathrm{SiO}_{2}$ & 14.9 & 39.1 & 13.6 & 45.2 & 73.3 \\
$\mathrm{Al}_{2} \mathrm{O}_{3}$ & 3.6 & 7.6 & 8.6 & 27.5 & 11.3 \\
$\mathrm{Fe}_{2} \mathrm{O}_{3}$ & 3.3 & 12.9 & 1.0 & 6.6 & 6.0 \\
$\mathrm{~K}_{2} \mathrm{O}$ & 0.8 & 1.1 & 0.5 & 2.2 & 1.9 \\
$\mathrm{Na}_{2} \mathrm{O}$ & 0.0 & 1.0 & 0.0 & 1.0 & 0.6 \\
$\mathrm{MgO}$ & 1.6 & 1.9 & 2.1 & 1.4 & 0.9 \\
$\mathrm{CuO}$ & 0.0 & 0.4 & 0.1 & 0.0 & 0.0 \\
$\mathrm{ZnO}$ & 0.1 & 0.7 & 0.1 & 0.1 & 0.0 \\
$\mathrm{Cl}$ & 0.1 & 0.3 & 2.2 & 0.0 & 0.0 \\
$\mathrm{SO}$ & 4.5 & 4.3 & 1.0 & 1.7 & 0.2 \\
$\mathrm{P}_{2} \mathrm{O}_{5}$ & 0.4 & 0.9 & 0.3 & 0.8 & 0.1 \\
$\mathrm{TiO}_{2}$ & 0.3 & 1.1 & 0.7 & 1.5 & 0.4 \\
Others & 0.4 & 1.9 & 0.2 & 2.1 & 0.6 \\
LOI & 2.2 & 9.2 & 14.6 & 5.3 & 3.6 \\
\hline Specific density $\left[\mathrm{g} \mathrm{cm}^{-3}\right]$ & 3.10 & 2.69 & 2.71 & 2.32 & 2.68 \\
\hline
\end{tabular}




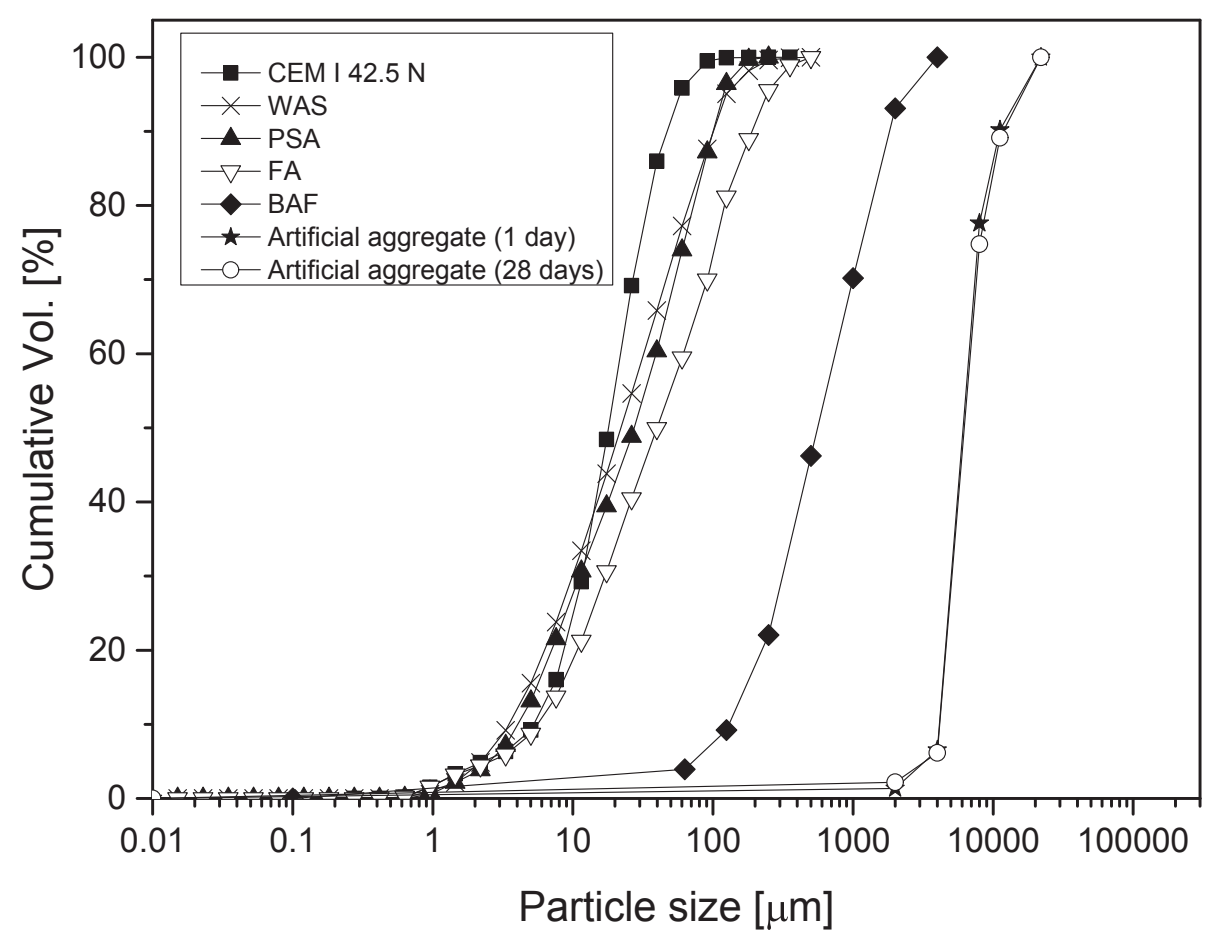

Fig. 1. The particle size distribution of raw materials and the produced artificial aggregate.

during the utilization of the disc pelletizer as described in our study. The disc pelletizer used for the pelletization process has a diameter of $100 \mathrm{~cm}$ and collar height of $15 \mathrm{~cm}$. The angle of the disc is fixed at $45^{\circ}$ and the speed is $15 \mathrm{rpm}$ (Gesoğlu et al., 2007). Considering the speed, and collar height of the disc, about $10 \mathrm{~kg}$ of material is fed for each running cycle. The pelletizing procedure is shown in Fig. 3.

Firstly, the raw materials are mixed in a concrete mixer to obtain a homogenously mixed material, and then the material is fed to the disc. A certain amount of water is sprayed during the first 5 min for the generation of new nuclei. Then the disc is continuously run for the generation and compaction of granulates; the total time used for one cycle is around $15 \mathrm{~min}$. After one cycle, the green granulates

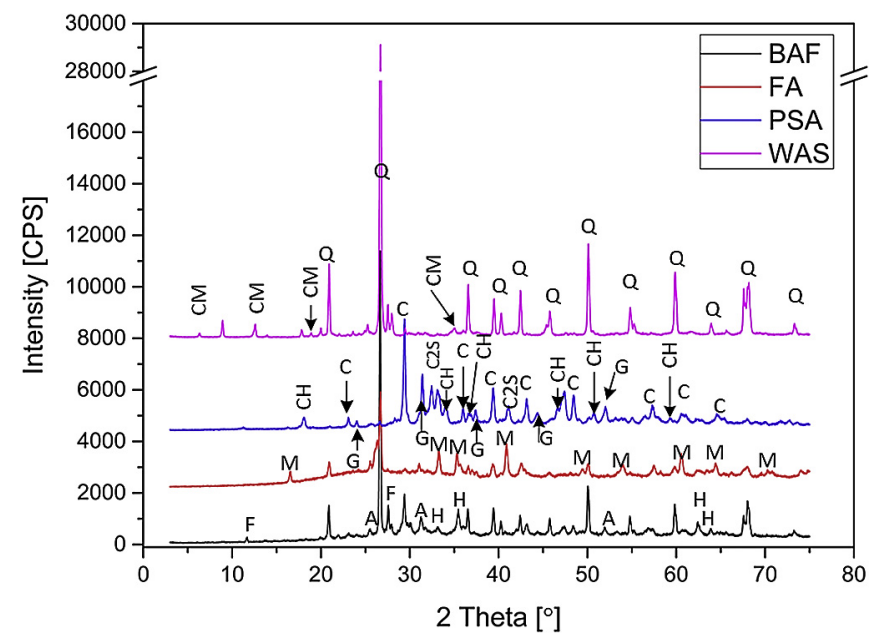

Fig. 2. The XRD pattern of the raw materials used for pelletization (Q-Quartz; CCalcite; CH-Portlandite; G-Gehlenite; CS-Calcium silicate; M-Mullite; CM-Chlorite mineral; F-Feldspar; H-Hematite; A-Anhydrite.). are collected and cured in sealed plastic film; around $100 \mathrm{~kg}$ of granulates in total is produced for further tests. The proportions of the materials used (based on total dried mass) is $10 \%$ OPC, $20 \%-80 \%$ BAF (with a moisture content of around 22\% wt.), 5\% WAS (with a water content of 53\% wt.), and 5-65\% FA and PSA. The determination of these proportions will be discussed in Section 3.

\section{- Characterization of produced aggregates}

After a certain curing time, a batch of aggregate is collected for relevant tests. The bulk density of the aggregates is determined following EN1097-3, (1998) and the water absorption of the aggregate is measured following the EN 1097-6, (2013), the value is equal to the average of three tested values. The individual pellet strength is tested using a similar test method to the one described and used in (Gesoğlu et al., 2007, 2012) 45 pellets are chosen to be tested for each curing age. The crushing resistance of the aggregates is also evaluated after different days of curing following EN 130551, (2002) (Annex A, procedure 1) to describe the strength of the produced aggregates and three samples are tested for each value. Optical microscopy and scanning electron microscopy (SEM, Quanta 650 FEG, FEI) are used to observe the cross section of the pellet.

\section{- Application of artificial aggregates in concrete}

The produced aggregate is used in concrete as aggregates with a proportion of $50 \%$ and $100 \%$ replacement by volume of the natural quartz aggregate $(2-8 \mathrm{~mm})$. Concrete cubes with artificial aggregates $\left(150 \times 150 \times 150 \mathrm{~mm}^{3}\right)$ are produced; the proportions used are: cement $280 \mathrm{~kg} / \mathrm{m}^{3}$, sand $(0-4 \mathrm{~mm}) 830 \mathrm{~kg} / \mathrm{m}^{3}$, and the gravel (2-8 mm) $1248 \mathrm{~kg} / \mathrm{m}^{3}$. The water to cement ratio is 0.5 for samples with $50 \%$ gravel replacement, and 0.6 for samples with $100 \%$ gravel replacement in order to get a similar flowability due to the high water absorption of artificial aggregates. The compressive strengths of the cubes are determined after 28 days. 


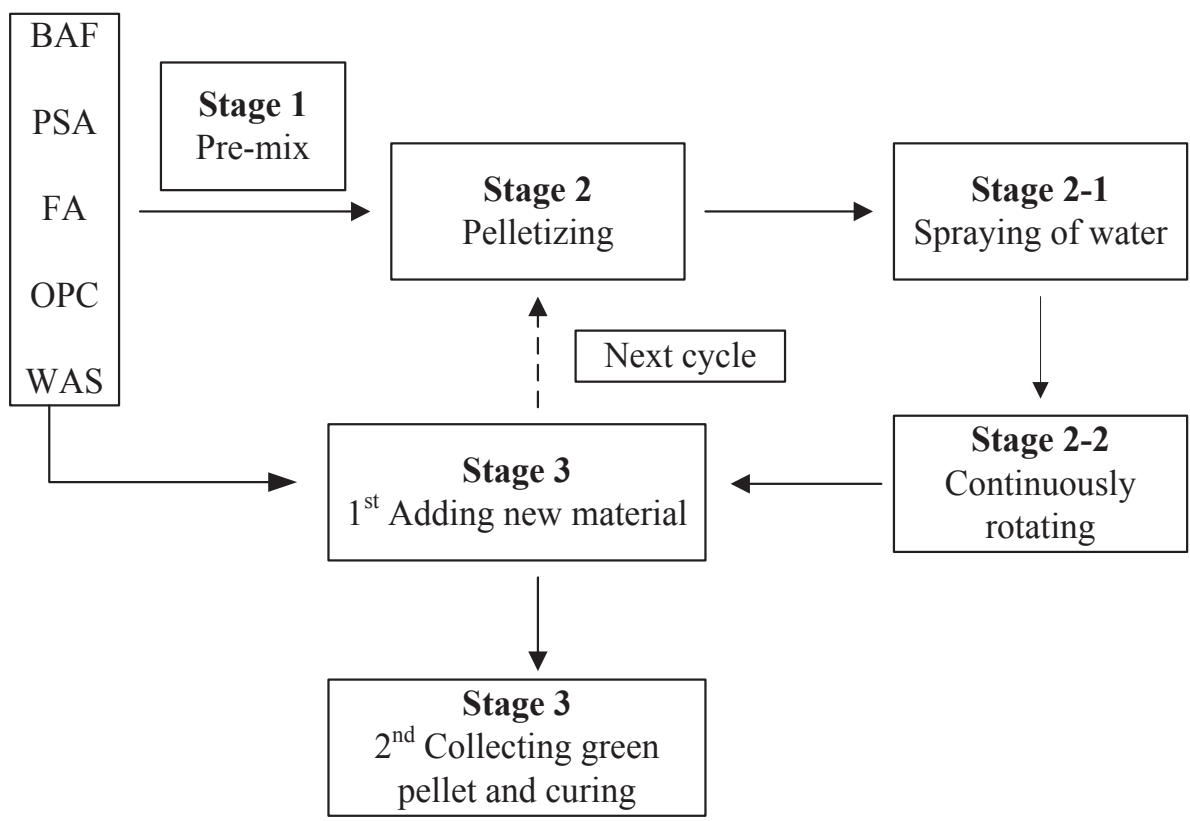

Fig. 3. The pelletizing procedure.

\section{- Leaching property evaluation}

To estimate the environmental impact of the BAF and the generated aggregate, column leaching tests according to Dutch standard NEN 7383, (2003) are performed on the representative samples. The liquid to solid ratio is kept at $10 \mathrm{l} / \mathrm{kg}$; during the test, the water is forced to flow through the material from the bottom to the top of the container for a certain period. The concentration of chemical elements in the eluate is analysed using inductively coupled plasma-atomic emission spectrometry (ICP-AES) according to NEN 6966, (2005), and the content of chloride and sulphate is determined through high performance liquid chromatography (HPLC) following NEN-EN-ISO 10304-2, (1996). The leaching values of studied elements are compared with the limit values according to the Dutch legislation (Soil Quality Decree, 2008). The column leaching test is also performed on the crushed concrete cubes to observe the leaching properties of recycled concrete. The concrete cubes are crushed under $4 \mathrm{~mm}$ and then column leaching as described above is conducted.

\section{Results and discussions}

\subsection{Proportion optimization of raw materials for pelletization}

The compatibility of the chosen available industrial solid wastes and MSWI BAF need to be firstly investigated and then the proportions of these solid wastes will be determined for the pelletization.

It is reported that the increasing amount of binders results in higher pellet strength, lower water absorption, etc. (Thomas and Harilal, 2015; Dutta et al., 1997a). It is also noticed in nowadays research that generally the cement dosage is around $10 \%$ of the total mass, and it can be $4 \%-6 \%$ when the binder is finer (Dutta et al., 1997a). Hence, the amount of the binder is controlled at $10 \%$ of the total solid mass in order to compare the results to others in literature. It is worth to mention that this binder dosage can be increased or decreased depending on the requirement of aggregate strength and cost in practical conditions. The initial water contents of the mixed raw materials are important for the growth of the new pellet, and was normally controlled at $21 \%-31 \%$ in others' work (Gesoğlu et al., 2007, 2012; Manikandan and Ramamurthy, 2008; Güneyisi et al., 2013a, 2015a). Therefore, the total amount of the dried WAS that can be used is controlled to less than $5 \%$ of the total solid mass (due to the fact that its water content is around $45 \%-$ $55 \%$ ). Hence, the influence of the WAS amount on the cement hydration is not further studied.

The influence of PSA and FA on the cement hydration individually and integrally is evaluated by the isothermal calorimetric tests and results are shown in Figs. 4-6.

Fig. 4 demonstrates the heat development of samples mixed with cement and PSA. The heat flow peak occurred after $12 \mathrm{~h}$ of plain cement hydration (peak 2 in Fig. 4(a)) happens earlier when PSA is added (peak 1). The more PSA is added, the earlier the peaks appears. The height of this peak increases with the increasing amount of PSA. This peak in plain cement hydration represents the reaction of C3S (tricalcium silicate) with the production of calcium silicate hydrate (C-S-H) gel phase and calcium hydroxide. It can be addressed that the addition of PSA accelerates the cement hydration. Fig. 4(b) shows that the total heat released from samples with $10-20 \%$ PSA is higher than that of plain cement (from $104.6 \%$ to $101.1 \%$, compared to $100 \%$ - plain cement), and for samples with $30-60 \%$ PSA it is lower than that of plain cement (from $99.3 \%$ to $86.7 \%$ ), which demonstrates that the PSA contributes to the chemical reaction of the mixed samples. Hence, the addition of PSA for the pelletization is supposed to increase the strength of the pellets.

Fig. 5(a) shows that the height of the main hydration peak (peak 1) at around 20 h decreases with the increasing amount of FA; the duration of this peak of samples with FA is longer than that for the plain cement sample. There is a pozzolanic reaction after around 45-50 h (peak 2), which contributes to the additional hydration peak. The total heat released decreases with the increase of FA, and it is always lower than the plain cement sample (Fig. 5(b)). However, the decrease of the total heat is lower than the replacement ratio of FA. For instance, after $120 \mathrm{~h}$, the total heat released from the solid mixtures decreases from $283 \mathrm{~J} / \mathrm{g}$ (100\% OPC) to $156 \mathrm{~J} / \mathrm{g}$ (60\% FA addition), and its reduction is $45 \%$ (when 60\% FA is used as OPC replacement) compared with plain OPC. This indicates that the FA 
(a)

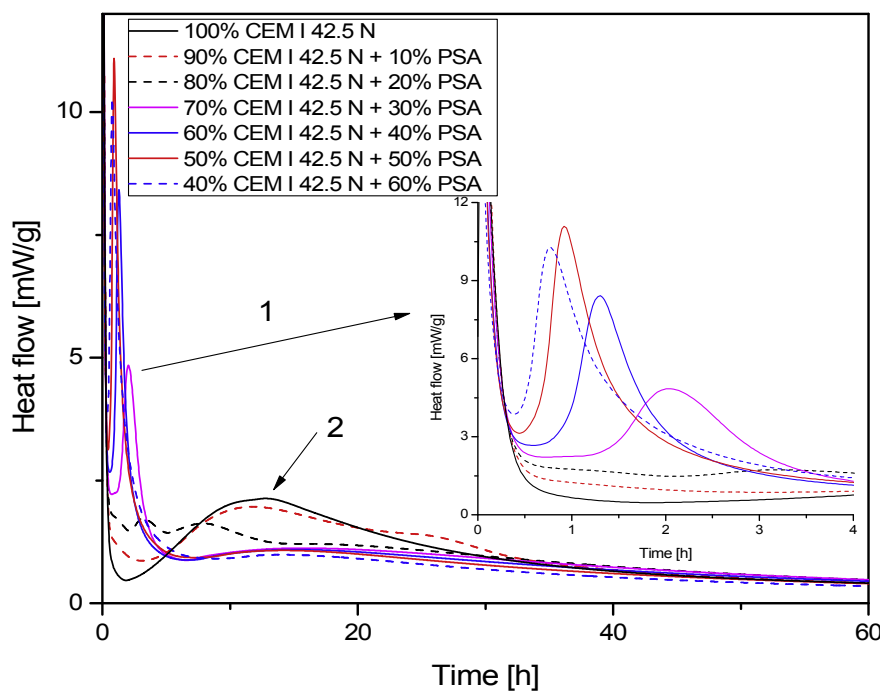

(b)

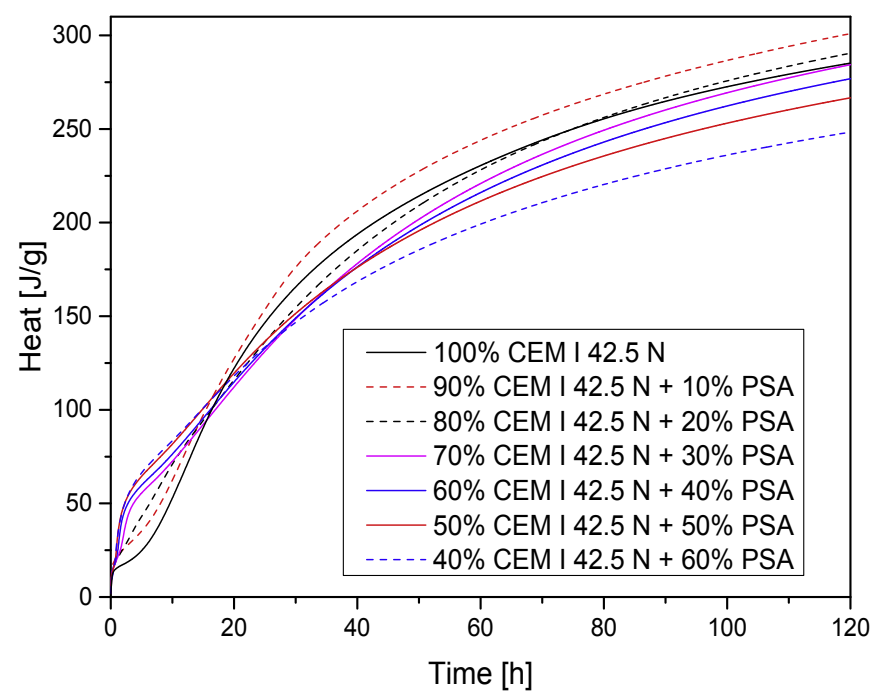

Fig. 4. The (a) heat evolution and (b) cumulative heat of cement with PSA normalized to total powder $(\mathrm{W} / \mathrm{B}=0.8)$.

(a)

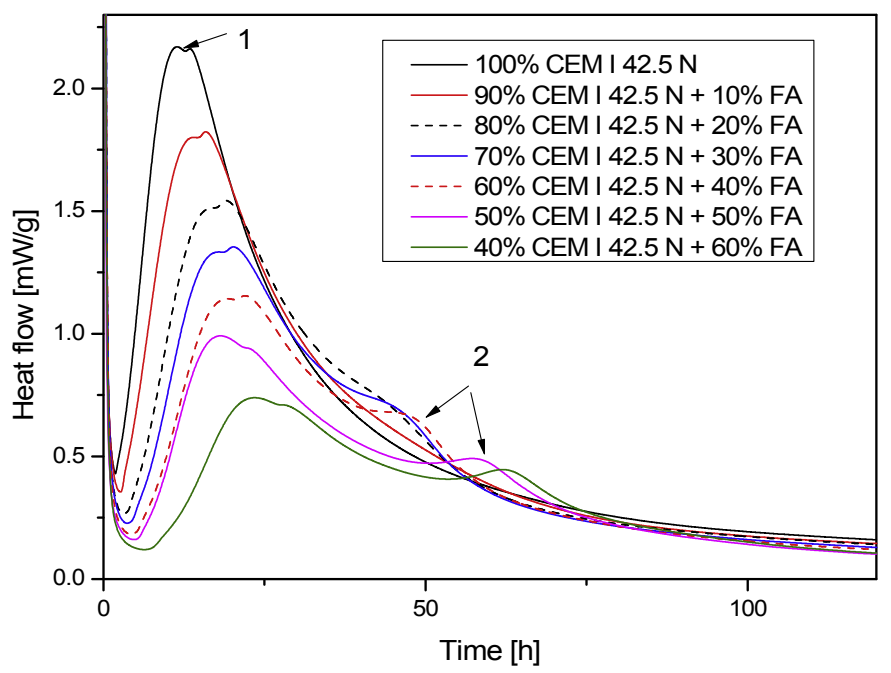

(b)

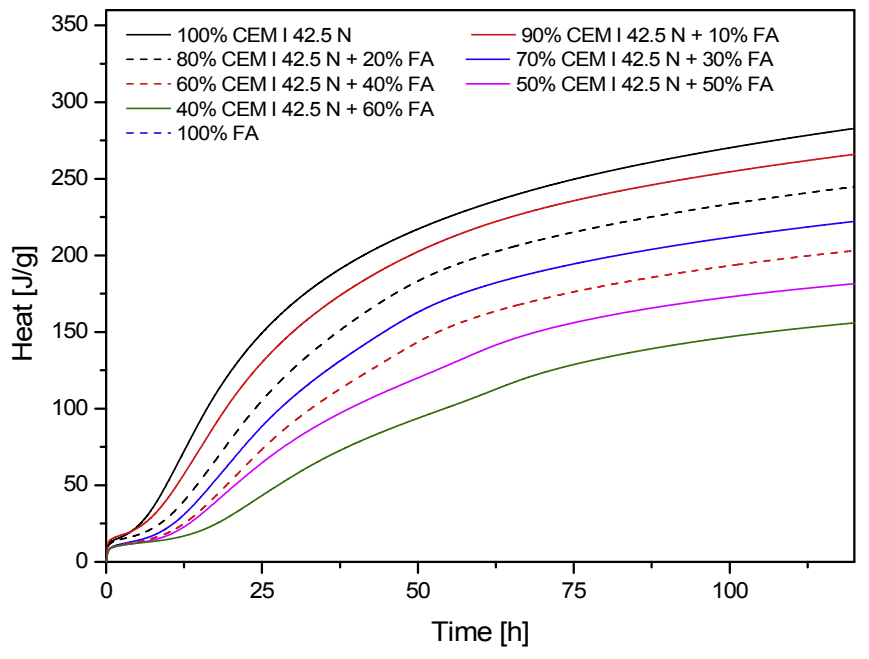

Fig. 5. The (a) heat evolution and (b) cumulative heat of cement with FA normalized to total powder $(W / B=0.8)$.

contributes with $15 \%$ to the heat release. It can be stated that the FA may have a slight contribution to the cement hydration at early age, even though it is much less compared to that of PSA.

From the above shown calorimetric results, it can be assumed that at early ages of aggregates curing, the strength of the pellets is mainly influenced by cement and PSA, while the use of FA can have positive effects on the pellet strength after long term curing, due to its slow pozzolanic properties (De Weerdt et al., 2011). To achieve a good combination of these two wastes, the relative proportions of FA and PSA should be determined when cement amount is fixed at $10 \%$ for pelletization. Fig. 6 shows the interaction between PSA and FA in cement system. It can be seen that, with a fixed amount of cement ( $10 \%$ wt.), the addition of PSA accelerates the cement hydration, and when PSA and FA is mixed with proportion $1: 1$, the total heat released is the closest to that of the plain cement sample. Therefore, the mix proportion of PSA and FA is 1:1 wt. of total PSA and FA for artificial aggregate production based on the calorimetric study.

The amount of BAF in this study is chosen based on its leaching properties, as well as the consideration of economic factors from the company (due to the fact that the BAF properties could differ from plant to plant, the design of the recipe could change. In our study, the amount of BAF is in the range of $20-80 \%$ of the total solids mass and the exact value is confidential).

To summarize, in the current study the proportions of the raw materials used are 10\% cement, 20\%-80\% BAF, 5\% WAS and the remaining part is a mixture of PSA and FA (1:1 wt.).

\subsection{Characteristics of the produced artificial aggregates}

\subsubsection{Artificial aggregate properties}

The particle size range of the produced aggregates is mainly around 2-8 $\mathrm{mm}$ (Fig. 1). It can be noticed that the 28-day sample has slightly higher amount of small particles ( $<2 \mathrm{~mm}, 1 \%$ more $)$ and 
(a)

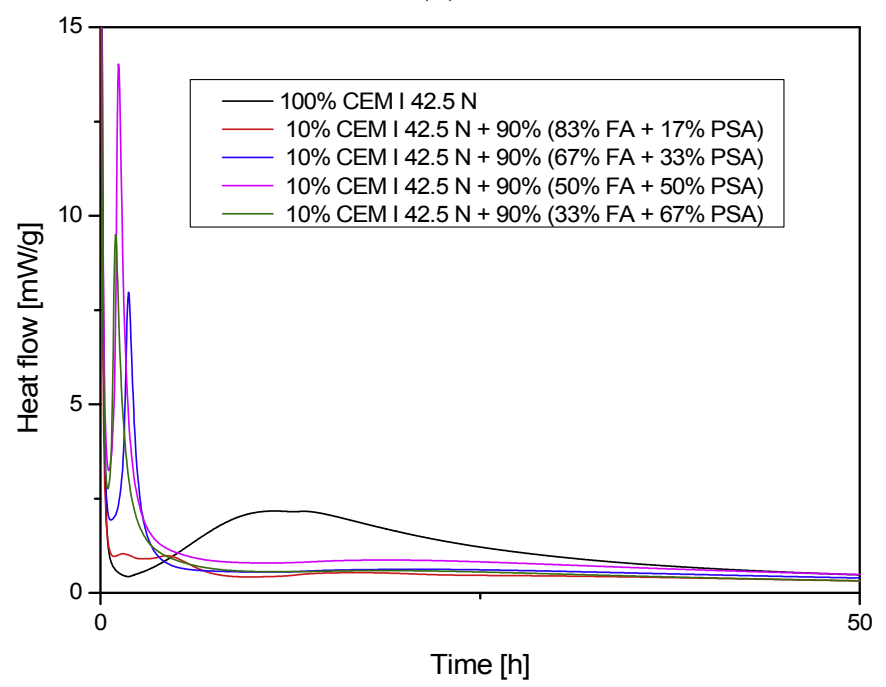

(b)

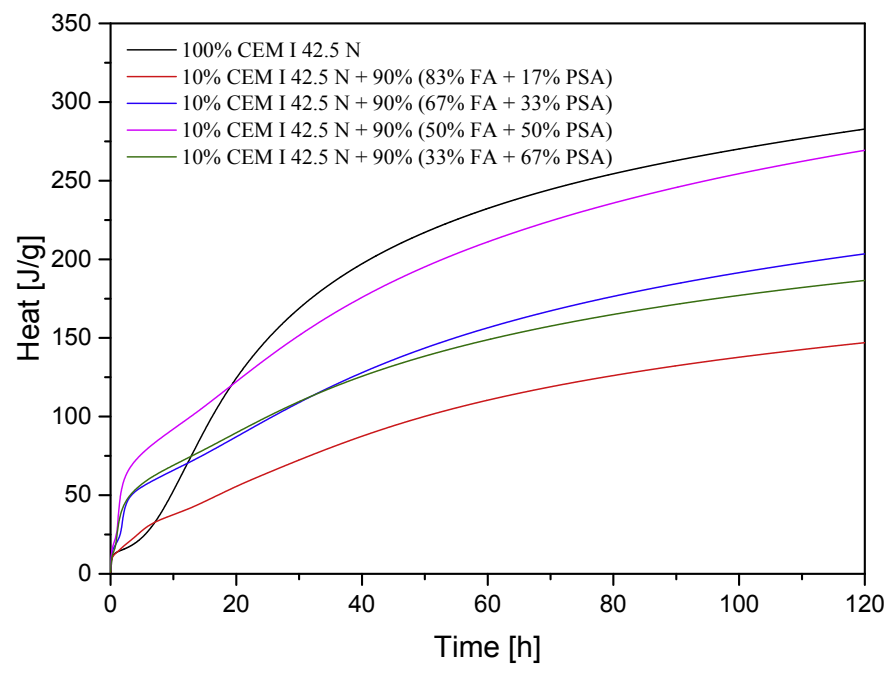

Fig. 6. The (a) heat evolution and (b) total heat of cement with PSA and FA normalized to total powder $(\mathrm{W} / \mathrm{B}=0.8)$.

a bit lower amount of coarse particles (>8 mm, 3\% less) compared with the 1 days samples, this could be due to the shrinkage of the pellets and the metallic $\mathrm{Al}$ in the BAF which may cause the cracking and break down of some pellets. Meanwhile, the powders on the pellet surface, which are less bonded into the matrix of the pellets may be removed by frictions when transferring the samples.

The specific density (Fig. 7(a)) of the aggregates produced is around $2.50 \mathrm{~g} / \mathrm{cm}^{3}$ which is slightly lower than that of natural quartz aggregates $\left(2.65 \mathrm{~g} / \mathrm{cm}^{3}\right)$, and the specific density of the fractions are very similar, which indicates the homogeneity of the produced aggregate. It can be noticed as well that the specific densities are decreasing slightly with the curing time; this could be attributed to the hydration of cement, the hydration product of which fills the pores inside the aggregate, and eventually decreases the porosity of the aggregates and finally their shrinkage. This could be further confirmed by the loose bulk density of the aggregate above $4 \mathrm{~mm}$, which shows an increasing trend along with the curing days (Fig. 7(b)). The loose bulk density of the aggregate above $4 \mathrm{~mm}$ is lower than $1200 \mathrm{~kg} / \mathrm{m}^{3}$, hence this aggregate fraction can be defined as lightweight aggregate according to EN 13055-1, (2002). The apparent density of the produced aggregate is $2323-2358 \mathrm{~kg} / \mathrm{m}^{3}$; its oven dried particle density is $1709-1730 \mathrm{~kg} / \mathrm{m}^{3}$, and the saturated and surface-dried particle density is $1975-1988 \mathrm{~kg} / \mathrm{m}^{3}$.

Fig. 8 shows the water absorption of the produced aggregates above $4 \mathrm{~mm}$. The $24 \mathrm{~h}$ water absorption after 28 days curing is around $14.9 \%$, which is lower compared with the artificial aggregate produced by fly ash in literature which is $21.2 \%$ (Güneyisi et al., 2015a) and 18.7-21.2\% (Thomas and Harilal, 2015), etc. It can be seen that the water absorption has a decreasing trend along with the curing time, and the difference between 7 and 28 days cured samples is small. Moreover, the water absorption increases significantly during the first hour. After $5 \mathrm{~min}$, the water absorption already reach $94 \%$ of the 24 h' water absorption for the 1-day cured (a)

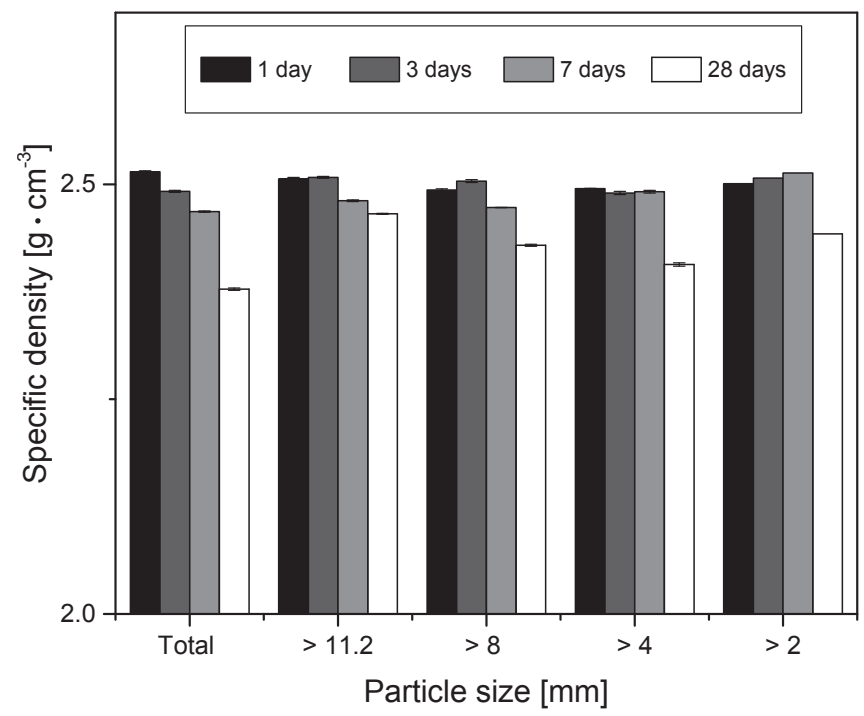

(b)

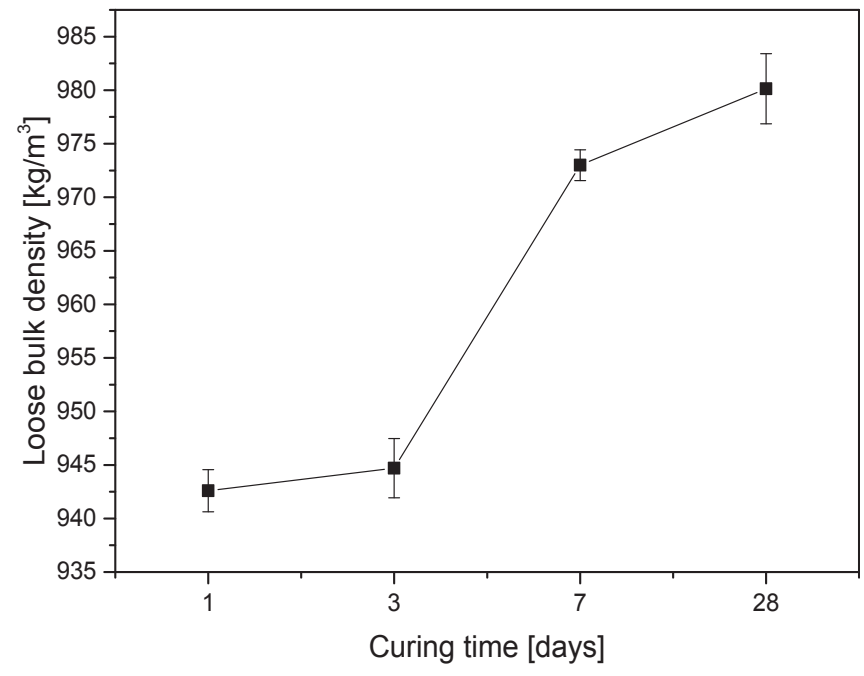

Fig. 7. The density of the artificial aggregate after different curing times. 


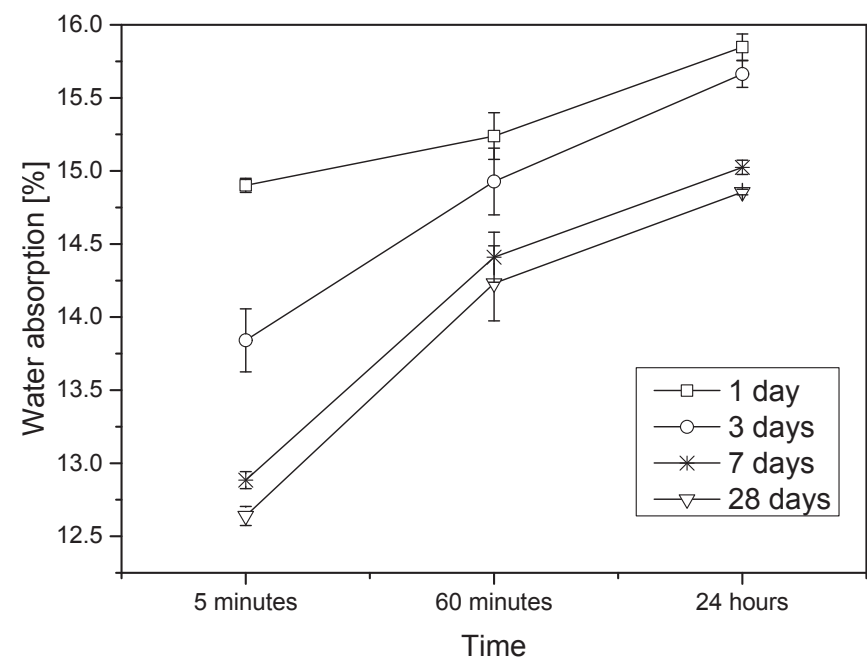

Fig. 8. The water absorption of the artificial aggregate after different curing ages.

sample, and this value is decreasing with the curing days (from $88 \%$ to $85 \%$ for 3-day and 28-day cured samples, respectively). After $1 \mathrm{~h}$, the water absorption of all the samples reach around 95-96\% of their 24 h' water absorption, respectively. It can be concluded that, the porosity of the artificial aggregate is decreasing along with the curing time, which also indicates the hydration of the binder. The water absorption reflects the porosity of the aggregate, which is related to its strength. For the artificial aggregate, it also reflects the compaction of the pellets during the pelletizing procedure.

The strength of the pellets depends on the binder dosage and the microstructure of the pellet (void ratio/porosity of the pellet). It can be seen in Fig. 9 that the strength of the individual pellets increases with the curing age, and after 7 days the pellet strength is around $84 \%$ of its 28 -day pellet strength; the pellet strength also

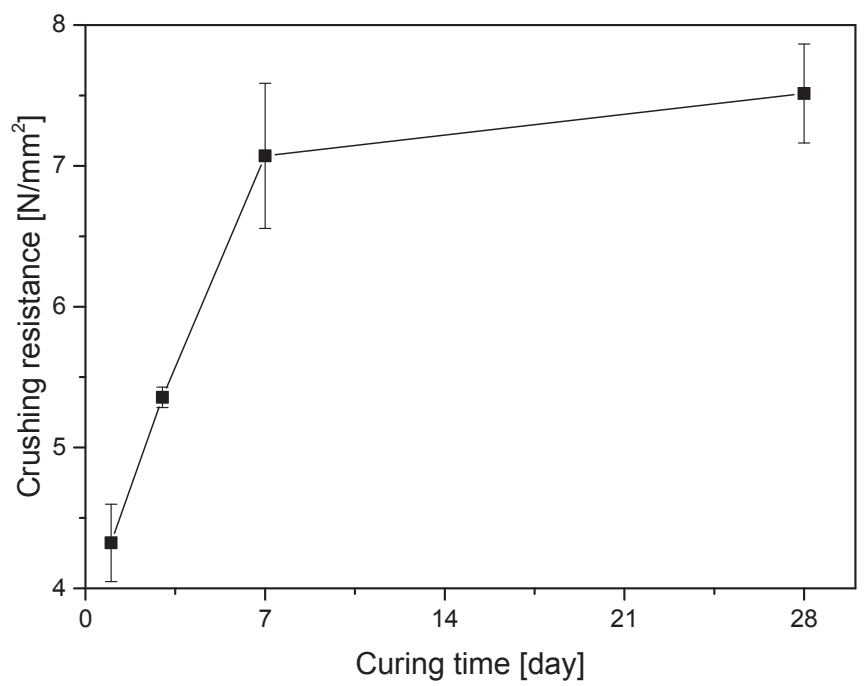

Fig. 10. The crushing resistance of the produced artificial aggregates.

increases with the particle size (around $125 \mathrm{~N}-650 \mathrm{~N}$ for pellet size from 4 to $16 \mathrm{~mm}$ ); these findings are in agreement with the results in (Gesoğlu et al., 2007, 2012). However, the results of the individual pellets strength are quite dispersing, as this test would be influenced significantly by the chosen pellets. Therefore, the crushing resistance of the aggregate according to EN 13055-1, (2002) was also evaluated to demonstrate the strength of the produced aggregates. The result is shown in Fig. 10. It can be seen that the crushing resistance increases steeply during the first 7 days of curing; after that there is only a small increase. The crushing resistance of 7 days-cured samples achieves $94 \%$ of the 28 dayscured samples (around $7.5 \mathrm{~N} / \mathrm{mm}^{2}$ ). This results suggest that after 7 days, the artificial aggregates can be ready for use or for delivery in practical conditions.

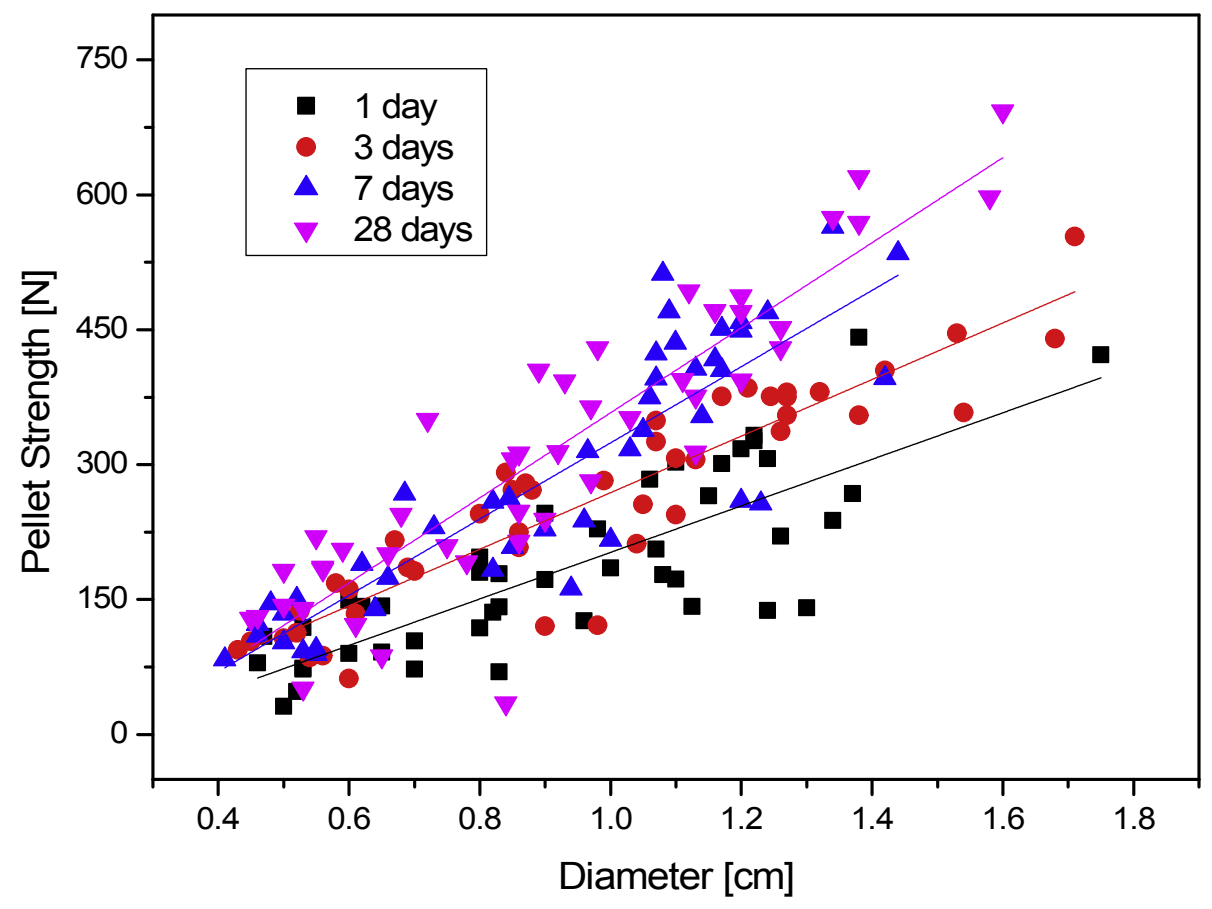

Fig. 9. The strength development of the produced pellets. 


\subsubsection{Comparison with other artificial aggregates}

In literature (Geetha and Ramamurthy, 2010a; Gesoğlu et al., 2004, 2007, 2012, 2014; Thomas and Harilal, 2015; Dutta et al., 1992; Cioffi et al., 2011; Geetha and Ramamurthy, 2013; Bui et al., 2012; Colangelo et al., 2015; Manikandan and Ramamurthy, 2008; Dutta et al., 1997b; Baykal and Doven, 2000; Güneyisi et al., 2015a), the particle size of the cold bonded lightweight aggregates was below $20 \mathrm{~mm}$ and the bulk density was between 800 and $1600 \mathrm{~kg} / \mathrm{m}^{3}$. The water absorption of the pellets was between 14 and 27\%. Gesoğlu et al. (2007) applied the cold bonded pelletizing technique to recycle fly ash from thermal power plant, in which the cement/fly ash ratio was 0.1 by weight and the pelletizing duration was $20 \mathrm{~min}$ in total (compared to $15 \mathrm{~min}$ in the present study). The produced aggregate had a particle size between 4 and $14 \mathrm{~mm}$, its water absorption was around 32\%, and individual particle crushing strength after 28-days curing was around $70-310 \mathrm{~N}$ for particle sizes from 6 to $14 \mathrm{~mm}(125-650 \mathrm{~N}$ for 4-16 mm in this study). Güneyisi et al. (2013b) produced a lightweight aggregate from a mix of powders of class $\mathrm{F}$ fly ash and Portland cement (9:1 of wt.) using the same device and pelletizer as described in Gesoğlu et al., (2007). The particle size of the produced aggregates was $4-16 \mathrm{~mm}$ with a water absorption of around $18 \%$, and its maximum pellet strength for pellets between 4 and $8 \mathrm{~mm}$ was $127 \mathrm{~N}$. Colangelo et al. (2015) used OPC, hydrated lime and coal fly ash as binding materials to recycle MSWI fly ash, and the binder accounted for around $30-50 \%$ of the total solid mass. The produced aggregate was surface treated using cement/coal fly ash mixture ( $1: 1$ by mass), and the total cement used for the pelletization accounted for around $14 \%$ of the total mass. The produced aggregates had a particle size of $4-18 \mathrm{~mm}$, and the crushing resistance is 2-6 MPa (7.5 MPa in the present study) and their maximum water absorption was $15 \%$. Comparing with other lightweight aggregates, the one produced in this study has a slightly lower water absorption, and higher pellet or crushing strength. Hence, it can be concluded that the production of the artificial lightweight aggregate using MSWI BAF together with other industrial solid powders is possible and the properties of the pellets are comparable or even better than the artificial aggregate reported in literature.

- Benefits of BAF in cold bonded aggregate from the mechanical point of view

Fig. 11 demonstrates the pellet microstructure produced with only powered materials (Fig. 11(a)) and with MSWI BAF (Fig. 11(b)). The higher crushing resistance of the artificial aggregate produced in this study with BAF particles compared with the others may be attributed to the following reasons: 1) the BAF particles in the pellet can act as a skeleton of the single pellet, which has the similar role as the aggregate acts in the concrete, resulting in the enhancement of the pellet strength compared with pellets produced with only powders. In another study (Cioffi et al., 2011), the incineration bottom ash was milled into powder for artificial aggregates production, which on one hand increased the production cost; while on the other hand, disrupted the contribution of bottom ash particles as skeleton to increase the pellet strength. Hence, the direct use of BAF for pelletization in this study is more beneficial; 2) the angular particle shape of BAF enhances the interlocking force and bonding between the powder matrix and the BAF particles, which increase the failure force of the pellet; 3 ) comparing the use of BAF with the use of only powder materials for producing artificial aggregate, with a fixed amount of binder and pellet size, the BAF has lower specific surface area than powder particles. This means less binder is needed for binding all the particles together and the pellet shape will be more stable (less powder will be removed from the surface of the pellets), similar to the statement in (Kim et al., 2016). Hence, with the same amount of binder, higher strength can be obtained for pellets with BAF than pellets with only powders.

- Transferring disadvantages of BAF into advantages in new products

Fig. 12 shows the cross section of the pellets with BAF under optical and scanning electron microscope, where the distribution of BAF particles, WAS and PSA can be seen clearly, and the BAF particles are well embedded into the matrix (Fig. 12(a)). It can be seen in Fig. 12(b) that the BAF particle is porous and has an irregular shape. Moreover, there are pores inside the BAF particles which contribute to the slightly lower specific density and lower loose bulk density of the produced aggregates as the results shown in Fig. 7. In general, the BAF has angular particle shapes and the surface of the particles is covered by dust, which contributes to the high water absorption during its application in mortar or concrete (Tang et al., 2015). However, these disadvantages of BAF in concrete can be positive factors during the pelletizing process in this study.

The BAF used in this work is collected from the MSWI bottom ash by sieving and it has a moisture content around $22 \%$ because of the water cooling of the bottom ash after the combustion. When the wet BAF is mixed with the powders, some powder particles are firstly agglomerated on the BAF particles due to their moisture content, which can shorten the pelletization duration to save energy consumption on a large-scale industrial production. When extra water is added, more fine powders are coated on the BAF particles, also the fine powders themselves start to agglomerate.
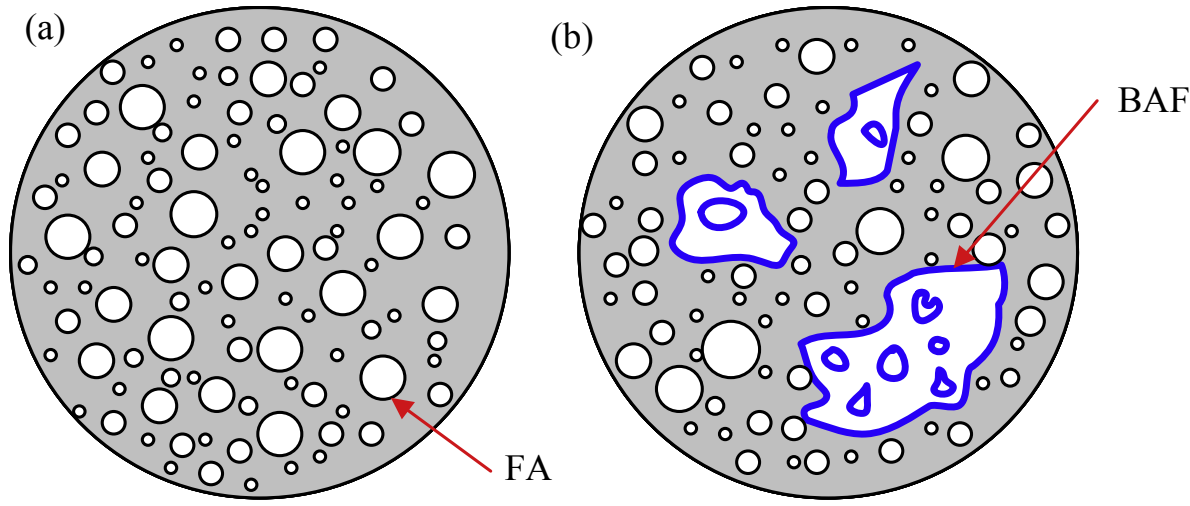

Fig. 11. Schematic representation of cross section of pellets produced (a) with only powders and (b) with addition of BAF. 
(a)

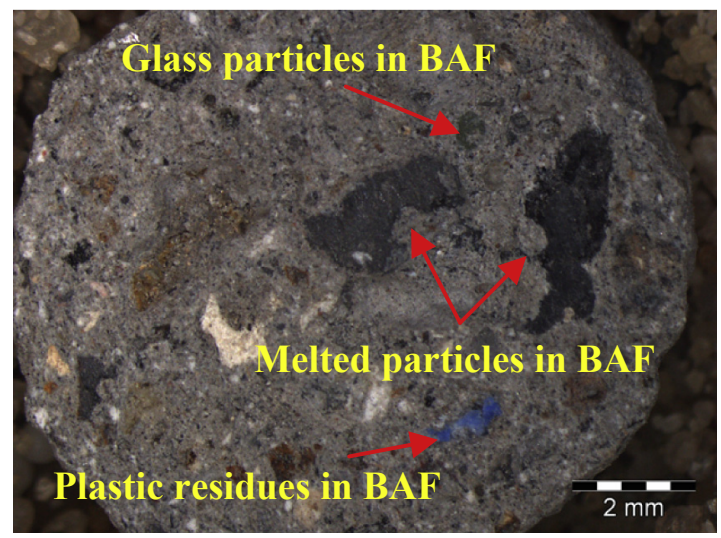

(b)

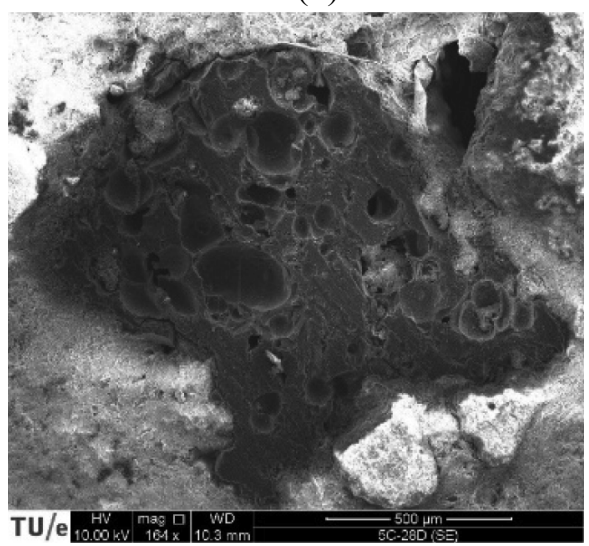

Fig. 12. The cross surface of a produced pellet (a) under optical microscope and a BAF particle (b) under scanning electron microscope.

Moreover, due to the bigger particle size compared to powder materials (such as fly ash) and rough surface structure, the compaction of the pellets during the pelletizing procedure is more efficient. The powder materials can easily absorb water on their surfaces, which generates a water layer, contributing to a longer compaction duration or a porous microstructure of the dried pellets. The agglomeration of powder and particles, and the compaction of the pellets happen during the whole pelletizing process.

It is observed during the tests that there are pellets which have cracks on their surface before crushing test or application. This could be attributed to the metallic $\mathrm{Al}$ in the BAF which reacts with alkalis and then generates $\mathrm{H}_{2}$, then leads to the cracking of the pellet before any external force is applied. Fig. 13 shows the cross section of a pellet and there is a piece of metallic $\mathrm{Al}$ found. Around the metallic Al piece there is a white trace observed, which might be the reaction rim of aluminium hydroxide due to the reaction of metallic Al with the alkaline surroundings during curing (Müller and Rübner, 2006). When the BAF is directly used in concrete, this gas formation could lead to the damage of the concrete like cracking and spalling (Tang et al., 2016). The same phenomenon takes place in the pellets. However, this does not mean that the crushing resistance of the whole pellet fraction will be decreased dramatically, because few pellets will undergo cracking (as shown

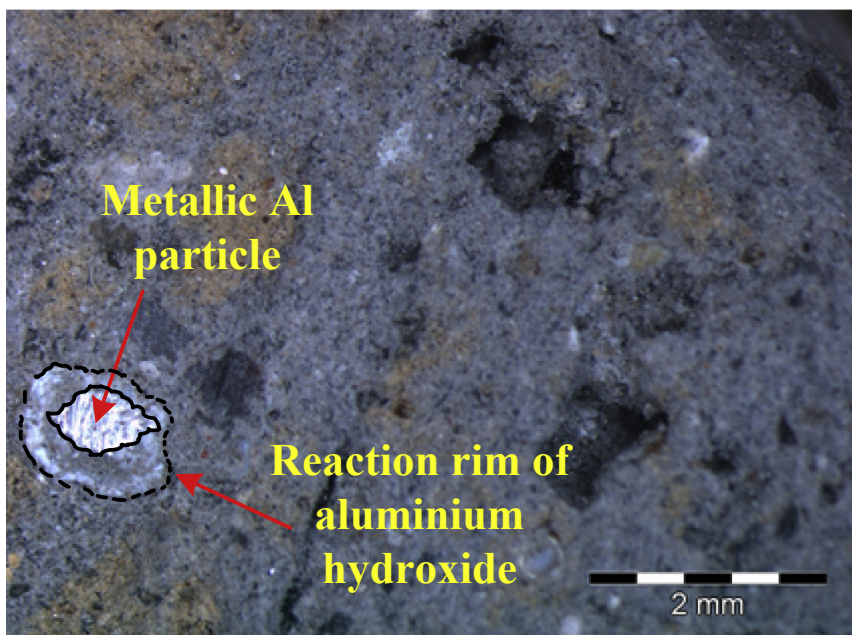

Fig. 13. The cross surface of a pellet under optical microscope where a metallic $\mathrm{Al}$ particle was found. in Fig. 1, the difference between the particle size distribution of samples after 1 day and 28 days curing is around 1-3\%). Meanwhile, this reaction can take place during the curing of the pellets, which means there will be less risk due to the metallic Al when the aggregates are used in concrete. Hence, in the application of artificial aggregate with BAF, the metallic $\mathrm{Al}$ is not a problem anymore.

Compared with traditional cold bonded artificial aggregate, the use of BAF is of more beneficial considering both the properties of produced pellets and the recycling of BAF. Therefore, the cold bonding technique is a good way to recycle the BAF for producing lightweight cold bonded aggregate together with other industrial waste powders.

\subsection{Evaluation of environmental properties of the artificial aggregate}

Due to the fact that the BAF is a waste residue from the combustion of various materials together, it contains some elements, whose leaching levels are limited by legislation on behalf of environmental safety. The column leaching results show that the BAF belongs to the IBC category (Soil Quality Decree, 2008) and the leaching of $\mathrm{Sb}, \mathrm{Cu}$, chloride and sulphate exceed the limit value of non-shaped material (Fig. 14) according to the soil quality decree (SQD) (Soil Quality Decree, 2008) in the Netherlands. The leaching of the other elements in the bottom ash in our study is well under the limits according to our previous study (Tang et al., 2015), therefore, in the current study only $\mathrm{Mo}, \mathrm{Sb}, \mathrm{Cu}$, chloride and sulphate are observed during the leaching test.

It is shown that BAF contains high amounts of $\mathrm{Cu}-$ around $3100 \mathrm{mg} / \mathrm{kg}$ of dry solid (d.s.), chloride $(2100 \mathrm{mg} / \mathrm{kg}$ d.s. $)$ and sulphate $(22,900 \mathrm{mg} / \mathrm{kg}$ d.s. $)$, and also $\mathrm{Sb}(83 \mathrm{mg} / \mathrm{kg}$ d.s. $)$ and Mo (19 $\mathrm{mg} / \mathrm{kg}$ d.s.). The leachability of the elements is calculated by dividing the total amount of the elements in the BAF by their leached out amount from the tested sample (BAF or artificial aggregate), respectively. The leaching level shows that chloride and sulphate in BAF has quite high leachability during the column test (around $45.2 \%$ of the total chloride and $48 \%$ of the total sulphate from the BAF is leached out, respectively).

The leaching of the artificial aggregate after 28 days curing shows that the Mo and chloride leaching exceed the limit value for non-shaped materials in the Dutch legislation (Soil Quality Decree, 2008). It can be seen that the leaching of the other investigated elements is well under this limit value. The leachability of $\mathrm{Cu}$ and Mo in the artificial aggregate increase compared with that of the BAF, especially for Mo which increases more than 3 times (Meima 
(a)

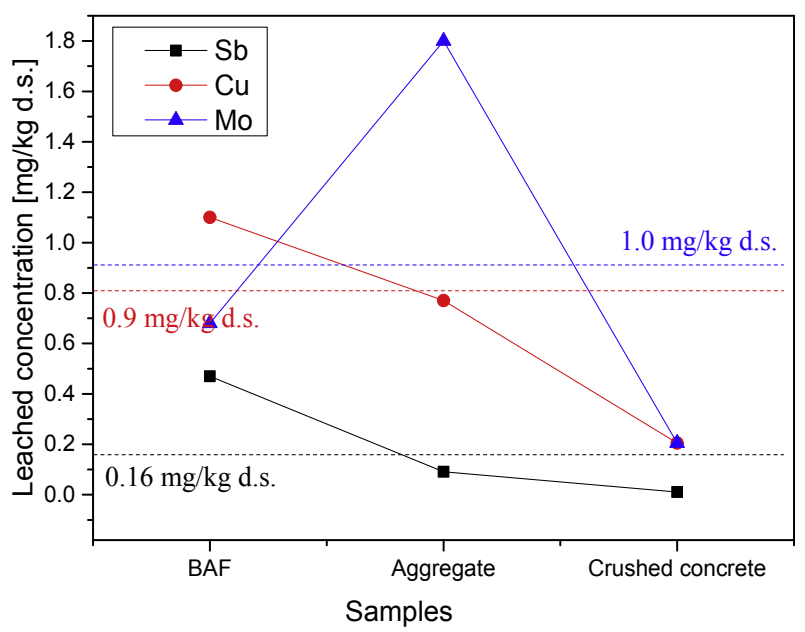

(b)

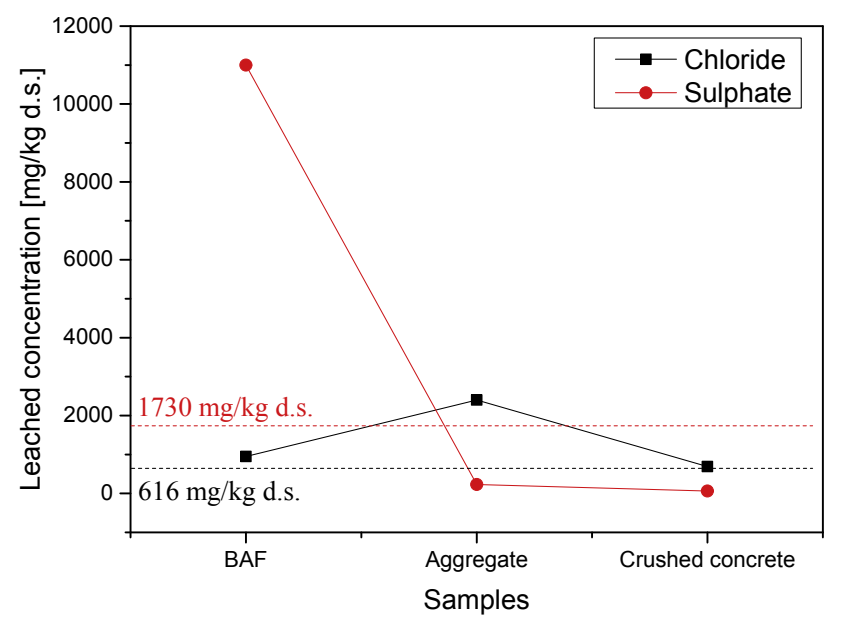

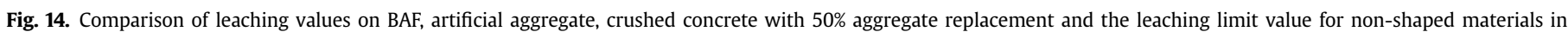
legislation (Soil Quality Decree, 2008) (dash - straight line).

et al., 2002). The leachability of Sb and sulphate in the artificial aggregate decreases compared with that of the BAF and the sulphate leaching decreased dramatically. For chloride, the total amount in the artificial aggregate is $0.3 \%$ (test value), and the leached out amount is $0.24 \%$, indicating that the chloride in the artificial aggregate is highly leachable.

Considering the binding capacity of these elements, it seems that $\mathrm{Sb}$ and sulphate are well bound, for the others the leaching capacity is increased. This is mostly attributed to the influence of the pH (Meima et al., 2002). The sulphate leaching is improved significantly in the artificial aggregate; this could be attributed to the fact that the sulphate in the BAF could contribute to the cement hydration (Tang et al., 2015). For the leaching of chloride, the high amount in the PSA ( $2 \%$, Table 1$)$ contributes to the higher leaching of chloride compared with calculated leaching based on the BAF only.

The leaching properties of the BAF will vary between plants, and also the leaching legislation on the BAF and aggregate with BAF are different between countries, the leaching properties can be adjusted by changing the amount of BAF or binder used according to specific requirements. Additionally, the produced aggregate can be used as aggregate replacement in concrete, even if its leaching properties do not meet the requirement for non-shaped materials, by controlling its replacement ratio to guarantee the leaching of the final shaped concrete products complies with the environmental legislation (Soil Quality Decree, 2008). In this way, the concrete with artificial aggregate, the leaching of levels under the limit value, will be the final product available for further application, considering the environmental legislation. Therefore, it is of interest to study the properties of concrete with this artificial aggregate from the mechanic point of view, which is relevant to its applications in the construction field.

\subsection{Concrete properties with artificial aggregate}

The 28-day compressive strength of the concrete with this artificial aggregate decreases with the increasing amount of aggregate replacement, from $37.1 \mathrm{MPa}$ to $27.7 \mathrm{MPa}$ when the replacement ratio of natural quartz aggregate increases from $50 \%$ to $100 \%$. This is attributed to the low strength of the artificial aggregate, similar to (Thomas and Harilal, 2015; Colangelo et al., 2015; Güneyisi et al., 2015a, 2015b).
It can be seen from Table 2 that, with a similar water to binder ratio, comparable particle size and replacement ratio of artificial aggregate, the compressive strength of concrete in this study with much less amount of cement, is higher than that in literature (Thomas and Harilal, 2015; Cioffi et al., 2011; Güneyisi et al., 2013b, 2015a; Gesoğlu et al., 2006, 2013).

It is reported in (Güneyisi et al., 2015a) that the concrete strength is decreased by $43 \%$ when the replacement ratio increased by $50 \%$ (from $50 \%$ to $100 \%$ ), and in (Güneyisi et al., 2015b) the concrete strength decreased by $18.5 \%$ after the replacement ratio increased from $30 \%$ to $45 \%$. It can be concluded that the concrete strength decrease is higher than the replacement ratio of the aggregate, which indicates the adding of the artificial aggregate could not contribute to the concrete strength properly. However, in this study, the compressive strength of the concrete decreased by $25 \%$ when the replacement ratio increased by $50 \%$ (from $50 \%$ to $100 \%$ ), which means the artificial aggregates contribute to the concrete strength. This could be attributed to the higher crushing strength of the artificial aggregate produced in this study than others. Therefore, it can be concluded that the application of artificial aggregate in concrete produced in this study has better results than other artificial aggregates.

There are several factors that influence the application of this kind of artificial aggregate in concrete: aggregate strength which relates to the concrete strength directly; water absorption which influences the fresh properties of concrete and aggregate density which is related to the concrete density. Fig. 15 shows the relationship between the water absorption, crushing resistance and loose bulk density of the artificial aggregate produced in this study. It can be seen that both the crushing resistance and loose bulk density of the aggregate have a linear relation with its water absorption.

A lower water absorption value means lower porosity of the aggregate. The loose bulk density of artificial aggregate is influenced by raw material density and aggregate porosity. The lower density of raw materials or higher porosity of aggregate results into lower loose bulk density. The crushing resistance in this study is related to the pellet strength (which is porosity related), packing of the sample during test, etc. Therefore, by adjusting the porosity of the artificial aggregate to determine its application in concrete where the concrete strength is more focused or the density of concrete, is more important. A lower porosity of the aggregate will 
Table 2

Literature summary of cold bonded aggregate application.

\begin{tabular}{|c|c|c|c|c|c|}
\hline Reference & Water to binder ratio & Cement $\left[\mathrm{kg} / \mathrm{m}^{3}\right]$ & Diameter $[\mathrm{mm}]$ & Replacement ratio [\%] & Compressive strength [MPa] \\
\hline \multirow[t]{2}{*}{ This study } & 0.5 & 280 & $2-8$ & 50 & 37.1 \\
\hline & 0.6 & & & 100 & 27.7 \\
\hline \multirow[t]{3}{*}{ Ferone et al. (2013) } & 0.45 & 250 & $10-20$ & 100 & $20-28$ \\
\hline & & 350 & & & $21-30$ \\
\hline & & 450 & & & $21-30$ \\
\hline Cioffi et al. (2011) & 0.5 & 345 & $5-20$ & 100 & $12.8-25.8$ \\
\hline \multirow[t]{2}{*}{ Güneyisi et al. (2015a) } & 0.4 & 440 & $0.25-4$ & 50 & 37 \\
\hline & & & & 100 & 21 \\
\hline \multirow[t]{3}{*}{ Gesoğlu et al. (2004) } & 0.55 & 400 & $4-9.5$ & 30 & 22 \\
\hline & & & & 45 & 27 \\
\hline & & & & 60 & 21 \\
\hline Güneyisi et al. (2013b) & 0.55 & 400 & $4-16$ & 100 & 29 \\
\hline Gesoğlu et al. (2006) & 0.55 & 400 & $4-9.5$ & 100 & $23.2-37.8$ \\
\hline Gesoğlu et al. (2013) & 0.55 & 350 & $4-16$ & 100 & 27.5 \\
\hline
\end{tabular}

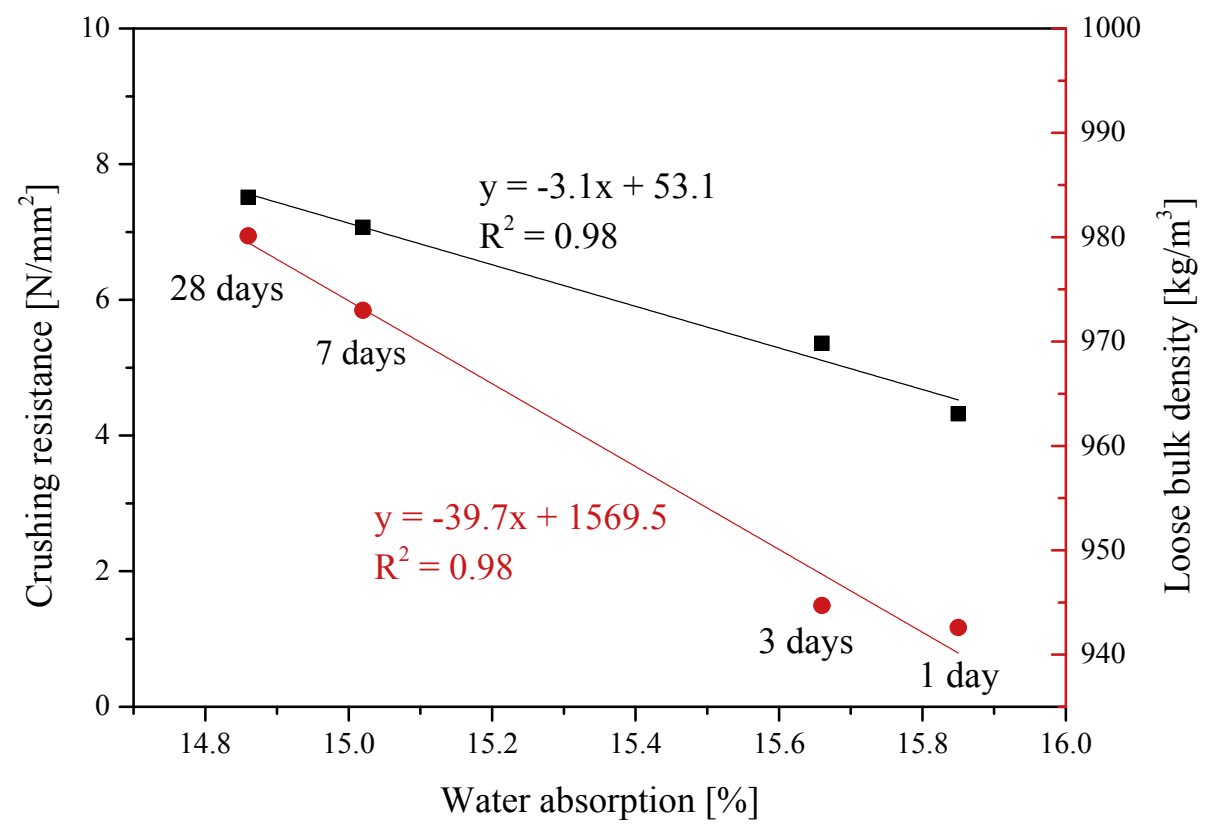

Fig. 15. The relation between water absorption, crushing resistance, and loose bulk density of the artificial aggregate.

also lead to decreased contaminant leaching.

The column leaching test on the crushed concrete samples with $50 \%$ aggregate replacement (Fig. 14) shows that its leaching concentrations of $\mathrm{Sb}, \mathrm{Cu}$, Mo and sulphate are far below their limit values according to SQD (Soil Quality Decree, 2008), which means this crushed concrete can be used as recycled aggregate again after its useful service life and the leaching of heavy metals would not be a problem. The leaching of chloride in the concrete is slightly higher than its limit value, which may limit its application in reinforced concrete. On the other hand, the binder amount of the concrete may influence the immobilization of contaminants; in general, more binder can reduce the leaching of heavy metals. Hence, for environmental considerations, the amount of produced aggregates applied in concrete can be modified according to the binder content in practice.

\section{Conclusion}

This paper presents the recycling of MSWI bottom ash fine particles (BAF, $0-2 \mathrm{~mm}$ ) through a cold bonding technique to produce lightweight aggregate, together with other waste powders.
From the results obtained in this paper the following conclusions can be drawn:

- The cold bonded technique, which is widely used to recycle the fly ash, slag, or quarry dust, can also be used to recycle MSWI BAF successfully.

- The properties of the lightweight aggregate produced in this study are comparable to or even better than the other artificial aggregates in literature. The use of BAF instead of only powders for pelletization has a positive effect on the properties of the artificial aggregate.

- The BAF particles act as skeleton in the pellets, playing a similar role as aggregates do in concrete and the angular BAF particle shape improves the interlocking force and bounding between the BAF particles and the powder matrix in the pellets, which contributes to a higher crushing resistance of the produced lightweight aggregates.

- Less cement is needed for producing artificial lightweight aggregate with similar crushing resistance using BAF than using only powders, due to the lower specific surface area of BAF compared with powders. 
- The leachability of sulphate and antimony in the artificial aggregate is decreased, while for copper it is increased due to the influence of $\mathrm{pH}$. The leaching of the sulphate, copper and antimony of the produced artificial aggregate is well under the limit value for the non-shaped material according to the legislation. The leaching of Mo and chloride can be further decreased in the final concrete samples by using a lower replacement ratio in case the requirements for non-shaped products are not met.

- Compared with concrete with other artificial aggregates, a higher compressive strength of concrete with artificial aggregate produced from BAF can be obtained due to the higher aggregate crushing resistance compared with other artificial aggregates. The leaching of heavy metals and salts from concrete with artificial aggregates is below the limit values according to the Dutch legislation, which indicates that the recycling and reuse of these concretes after their service life will comply with the current environmental legislation.

\section{Acknowledgement}

The authors gratefully thank the China Scholarship Council (China) and the Department of the Built Environment, Eindhoven University of Technology (the Netherlands) for supporting this research. The authors wish to express their gratitude to sponsor company - Attero and to the following sponsors of the Building Materials research group at TU Eindhoven: Rijkswaterstaat Grote Projecten en Onderhoud, Graniet-Import Benelux, Kijlstra Betonmortel, Struyk Verwo, ENCI HeidelbergCement, Rijkswaterstaat Zee en Delta-District Noord, Van Gansewinkel Minerals, BTE, V.d. Bosch Beton, Selor, GMB, Icopal, BN International, Eltomation, Knauf Gips, Hess AAC Systems, Kronos, Joma, CRH Europe Sustainable Concrete Centre, Cement\&BetonCentrum, Heros, Inashco, Keim, and Sirius International (in chronological order of joining).

\section{References}

Al-Rawas, A.A., Wahid Hago, A., Taha, R., Al-Kharousi, K., 2005. Use of incinerator ash as a replacement for cement and sand in cement mortars. Build. Environ. 40, 1261-1266. http://dx.doi.org/10.1016/j.buildenv.2004.10.009.

Baykal, G., Doven, A.G., 2000. Utilization of fly ash by pelletization process ; theory, application areas and research results. Resour. Conserv. Recycl. 30, 59-77.

Baykal, G., Döven, A.G., 2000. Utilization of fly ash by pelletization process; theory, application areas and research results. Resour. Conserv. Recycl. 30, 59-77. http://dx.doi.org/10.1016/S0921-3449(00)00042-2.

Berryman, C., Zhu, J., Jensen, W., Tadros, M., 2005. High-percentage replacement of cement with fly ash for reinforced concrete pipe. Cem. Concr. Res. 35, 1088-1091. http://dx.doi.org/10.1016/j.cemconres.2004.06.040.

Bin Mohd Sani, M.S.H., Bt Muftah, F., Ab Rahman, M., 2011. Properties of Waste Paper Sludge Ash (WPSA) as cement replacement in mortar to support green technology material. In: 3rd ISESEE 2011-Int. Symp. Exhib. Sustain. Energy Environ., pp. 1-3. http://dx.doi.org/10.1109/ISESEE.2011.5977117.

Bosmans, A., Vanderreydt, I., Geysen, D., Helsen, L., 2013. The crucial role of Wasteto-Energy technologies in enhanced landfill mining: a technology review. J. Clean. Prod. 55, 10-23. http://dx.doi.org/10.1016/j.jclepro.2012.05.032.

Brouwers, H.J.H., Augustijn, D.C.M., Krikke, B., Honders, A., 2007. Use of cement and quicklime to accelerate ripening and immobilize contaminated dredging sludge. J. Hazard. Mater. 145, 8-16. http://dx.doi.org/10.1016/j.jhazmat.2006. 10.074 .

Bui, L.A., Hwang, C., Chen, C., Lin, K., Hsieh, M., 2012. Manufacture and performance of cold bonded lightweight aggregate using alkaline activators for high performance concrete. Constr. Build. Mater. 35, 1056-1062. http://dx.doi.org 10.1016/j.conbuildmat.2012.04.032.

Cioffi, R., Colangelo, F., Montagnaro, F., Santoro, L., 2011. Manufacture of artificial aggregate using MSWI bottom ash. Waste Manag. 31, 281-288. http:/| dx.doi.org/10.1016/j.wasman.2010.05.020.

Colangelo, F., Cioffi, R., Montagnaro, F., Santoro, L., 2012. Soluble salt removal from MSWI fly ash and its stabilization for safer disposal and recovery as road basement material. Waste Manag. 32, 1179-1185. http://dx.doi.org/10.1016 j.wasman.2011.12.013.

Colangelo, F., Messina, F., Cioffi, R., 2015. Recycling of MSWI fly ash by means of cementitious double step cold bonding pelletization: technological assessment for the production of lightweight artificial aggregates. J. Hazard. Mater. 299, 181-191. http://dx.doi.org/10.1016/j.jhazmat.2015.06.018.

Cossu, R., Lai, T., Pivnenko, K., 2012. Waste washing pre-treatment of municipal and special waste. J. Hazard. Mater. 207-208, 65-72. http://dx.doi.org/10.1016/ j.jhazmat.2011.07.121.

De Weerdt, K., Ben Haha, M., Le Saout, G., Kjellsen, K.O., Justnes, H., Lothenbach, B., 2011. Hydration mechanisms of ternary Portland cements containing limestone powder and fly ash. Cem. Concr. Res. 41, 279-291. http://dx.doi.org/10.1016/ j.cemconres.2010.11.014.

Dutta, D.K., Bordolop, D., Gupta, S., Borthakur, P.C., Srinivasan, T.M., Patil, J.B., 1992. Investigation on cold bonded pelletization of iron ore fines using Indian slagcement. Int. J. Min. Process. 34, 149-159.

Dutta, D.K., Bordoloi, D., Borthakur, P.C., 1997a. Investigation on reduction of cement binder in cold bonded pelletization of iron ore fines. Int. J. Min. Process. 49, 97-105. http://dx.doi.org/10.1016/S0301-7516(96)00033-6.

Dutta, D.K., Bordoloi, D., Borthakur, P.C., 1997b. Investigation on reduction of cement binder in cold bonded pelletization of iron ore fines. Int. J. Min. Process. 49, 97-105. http://dx.doi.org/10.1016/S0301-7516(96)00033-6.

EN 1097-6, 2013. Tests for Mechanical and Physical Properties of Aggregates-Part 6: Determination of Particle Density and Water Absorption.

EN 13055-1, 2002. Lightweight Aggregates-Part 1: Lightweight Aggregates for Concrete, Mortar and Grout.

EN 933-2, 1995. Tests for Gepmetrical Properties of Aggregates-Part 2: Determination of Particle Size Distribution-Test Sieves, Norminal Size of Apertures.

EN1097-3, 1998. Test for Mechanical and Physical Properties of Aggregates-Part 3: Determination of Loose Bulk Density and Voids.

Ferone, C., Colangelo, F., Messina, F., Iucolano, F., Liguori, B., Cioffi, R., 2013. Coal combustion wastes reuse in low energy artificial aggregates manufacturing. Mater. (Basel) 6, 5000-5015. http://dx.doi.org/10.3390/ma6115000.

Geetha, S., Ramamurthy, K., 2010a. Environmental friendly technology of coldbonded bottom ash aggregate manufacture through chemical activation. J. Clean. Prod. 18, 1563-1569. http://dx.doi.org/10.1016/j.jclepro.2010.06.006.

Geetha, S., Ramamurthy, K., 2010b. Reuse potential of low-calcium bottom ash as aggregate through pelletization. Waste Manag. 30, 1528-1535. http:// dx.doi.org/10.1016/j.wasman.2010.03.027.

Geetha, S., Ramamurthy, K., 2013. Properties of geopolymerised low-calcium bottom ash aggregate cured at ambient temperature. Cem. Concr. Compos. 43 , 20-30. http://dx.doi.org/10.1016/j.cemconcomp.2013.06.007.

Gesoğlu, M., Özturan, T., Güneyisi, E., 2004. Shrinkage cracking of lightweight concrete made with cold-bonded fly ash aggregates. Cem. Concr. Res. 34, 1121-1130. http://dx.doi.org/10.1016/j.cemconres.2003.11.024.

Gesoğlu, M., Özturan, T., Güneyisi, E., 2006. Effects of cold-bonded fly ash aggregate properties on the shrinkage cracking of lightweight concretes. Cem. Concr. Compos. 28, 598-605. http://dx.doi.org/10.1016/j.cemconcomp.2006.04.002.

Gesoğlu, M., Özturan, T., Güneyisi, E., 2007. Effects of fly ash properties on characteristics of cold-bonded fly ash lightweight aggregates. Constr. Build. Mater. 21, 1869-1878. http://dx.doi.org/10.1016/j.conbuildmat.2006.05.038.

Gesoğlu, M., Güneyisi, E., Mahmood, S.F., Öz, H.Ö., Mermerdaş, K., 2012. Recycling ground granulated blast furnace slag as cold bonded artificial aggregate partially used in self-compacting concrete. J. Hazard. Mater. 235-236, 352-358. http://dx.doi.org/10.1016/j.jhazmat.2012.08.013.

Gesoğlu, M., Güneyisi, E., Alzeebaree, R., Mermerdaş, K., 2013. Effect of silica fume and steel fiber on the mechanical properties of the concretes produced with cold bonded fly ash aggregates. Constr. Build. Mater. 40, 982-990. http:// dx.doi.org/10.1016/j.conbuildmat.2012.11.074

Gesoğlu, M., Güneyisi, E., Özturan, T., Öz, H.Ö., Asaad, D.S., 2014. Self-consolidating characteristics of concrete composites including rounded fine and coarse fly ash lightweight aggregates. Compos. Part B Eng. 60, 757-763. http://dx.doi.org/ 10.1016/j.compositesb.2014.01.008.

González-Corrochano, B., Alonso-Azcárate, J., Rodas, M., 2009. Characterization of lightweight aggregates manufactured from washing aggregate sludge and fly ash. Resour. Conserv. Recycl 53, 571-581. http://dx.doi.org/10.1016/j.resconrec. 2009.04.008.

Green deal, (2012). https://www.rijksoverheid.nl/onderwerpen/duurzameeconomie/inhoud/green-deal.

Güneyisi, E., Gesoğlu, M., İpek, S., 2013a. Effect of steel fiber addition and aspect ratio on bond strength of cold-bonded fly ash lightweight aggregate concretes. Constr. Build. Mater. 47, 358-365. http://dx.doi.org/10.1016/j.conbuildmat. 2013.05.059.

Güneyisi, E., Gesoğlu, M., Pürsünlü, Ö., Mermerdaş, K., 2013b. Durability aspect of concretes composed of cold bonded and sintered fly ash lightweight aggregates. Compos. Part B Eng. 53, 258-266. http://dx.doi.org/10.1016/j.compositesb. 2013.04.070

Güneyisi, E., Gesoğlu, M., Altan, İ., Öz, H.Ö., 2015a. Utilization of cold bonded fly ash lightweight fine aggregates as a partial substitution of natural fine aggregate in self-compacting mortars. Constr. Build. Mater. 74, 9-16. http://dx.doi.org/ 10.1016/j.conbuildmat.2014.10.021.

Güneyisi, E., Gesoğlu, M., Booya, E., 2015b. Strength and permeability properties of self-compacting concrete with cold bonded fly ash lightweight aggregate. Constr. Build. Mater. 74, 17-24. http://dx.doi.org/10.1617/s11527-012-9874-6.

Keulen, A., van Zomeren, A., Harpe, P., Aarnink, W., Simons, H.A.E., Brouwers, H.J.H., 2015. High performance of treated and washed MSWI bottom ash granulates as natural aggregate replacement within earth-moist concrete. Waste Manag. 49, 83-95. http://dx.doi.org/10.1016/j.wasman.2016.01.010.

Kim, H.K., Ha, K.A., Lee, H.K., 2016. Internal-curing efficiency of cold-bonded coal bottom ash aggregate for high-strength mortar. Constr. Build. Mater. 126, 1-8. http://dx.doi.org/10.1016/j.conbuildmat.2016.08.125.

Li, X.-G., Lv, Y., Ma, B.-G., Chen, Q.-B., Yin, X.-B., Jian, S.-W., 2012. Utilization of 
municipal solid waste incineration bottom ash in blended cement. J. Clean. Prod. 32, 96-100. http://dx.doi.org/10.1016/j.jclepro.2012.03.038.

Luna Galiano, Y., Fernández Pereira, C., Vale, J., 2011. Stabilization/solidification of a municipal solid waste incineration residue using fly ash-based geopolymers. J. Hazard. Mater. 185, 373-381. http://dx.doi.org/10.1016/j.jhazmat.2010.08.127.

Manikandan, R., Ramamurthy, K., 2008. Effect of curing method on characteristics of cold bonded fly ash aggregates. Cem. Concr. Compos. 30, 848-853. http:// dx.doi.org/10.1016/j.cemconcomp.2008.06.006.

Meima, J.A., van der Weijden, R.D., Eighmy, T.T., Comans, R.N., 2002. Carbonation processes in municipal solid waste incinerator bottom ash and their effect on the leaching of copper and molybdenum. Appl. Geochem. 17, 1503-1513. http:// dx.doi.org/10.1016/S0883-2927(02)00015-X.

Müller, U., Rübner, K., 2006. The microstructure of concrete made with municipal waste incinerator bottom ash as an aggregate component. Cem. Concr. Res. 36, 1434-1443. http://dx.doi.org/10.1016/j.cemconres.2006.03.023.

NEN 6966, 2005. Environment - Analysis of Selected Elements in Water, Eluates and Destruates - Atomic Emission Spectrometry with Inductively Coupled Plasma.

NEN 7383, 2003. Uitloogkarakteristieken -Bepaling van de cumulatieve uitloging van anorganische componenten uit poeder- en korrelvormige materialen met een vereenvoudigde procedure voor de kolomproef - Vaste grond- en steenachtige materialen.

NEN-EN-ISO 10304-2, 1996. Water Quality-Determination of Dissolved Anions by Liquid Chromatography of Ions-Part 2: Determination of Bromide, Chloride, Nitrate, Nitrite, Orthophosphate and Sulfate in Waste Water:

Rahman, M.A., Bakker, M.C.M., 2013. Sensor-based control in eddy current separation of incinerator bottom ash. Waste Manag. 33, 1418-1424. http://dx.doi.org/ 10.1016/j.wasman.2013.02.013.

Santos, R.M., Mertens, G., Salman, M., Cizer, O., Van Gerven, T., 2013. Comparative study of ageing, heat treatment and accelerated carbonation for stabilization of municipal solid waste incineration bottom ash in view of reducing regulated heavy metal/metalloid leaching. J. Environ. Manag. 128C, 807-821. http:// dx.doi.org/10.1016/j.jenvman.2013.06.033.

Soil Quality Decree, Https://zoek.officielebekendmakingen.nl/stb-2. (2008). https:// zoek.officielebekendmakingen.nl/stb-2007-469-v1.html.

Tang, P., Florea, M.V.A., Spiesz, P., Brouwers, H.J.H., 2015. Characteristics and application potential of municipal solid waste incineration (MSWI) bottom ashes from two waste-to-energy plants. Constr. Build. Mater. 83, 77-94. http:// dx.doi.org/10.1016/j.conbuildmat.2015.02.033.

Tang, P., Florea, M.V.A., Spiesz, P., Brouwers, H.J.H., 2016. Application of thermally activated municipal solid waste incineration (MSWI) bottom ash fines as binde substitute. Cem. Concr. Compos. 70, 194-205. http://dx.doi.org/10.1016/ j.cemconcomp.2016.03.015.

Thomas, J., Harilal, B., 2015. Properties of cold bonded quarry dust coarse aggregates and its use in concrete. Cem. Concr. Compos. 62, 67-75. http://dx.doi.org/ 10.1016/j.cemconcomp.2015.05.005.

Voglar, G.E., Leštan, D., 2011. Efficiency modeling of solidification/stabilization of multi-metal contaminated industrial soil using cement and additives. J. Hazard. Mater. 192, 753-762. http://dx.doi.org/10.1016/j.jhazmat.2011.05.089.

Volland, S., Brötz, J., 2015. Lightweight aggregates produced from sand sludge and zeolitic rocks. Constr. Build. Mater. 85, 22-29. http://dx.doi.org/10.1016/ j.conbuildmat.2015.03.018.

Wong, H.S., Barakat, R., Alhilali, A., Saleh, M., Cheeseman, C.R., 2015. Hydrophobic concrete using waste paper sludge ash. Cem. Concr. Res. 70, 9-20. http:// dx.doi.org/10.1016/j.cemconres.2015.01.005.

Xuan, D., Zhan, B., Poon, C.S., Zheng, W., 2016a. Innovative reuse of concrete slurry waste from ready-mixed concrete plants in construction products. J. Hazard Mater. 312, 65-72. http://dx.doi.org/10.1016/j.jhazmat.2016.03.036.

Xuan, D., Zhan, B., Poon, C.S., 2016b. Assessment of mechanical properties of concrete incorporating carbonated recycled concrete aggregates. Cem. Concr. Compos. 65, 67-74. http://dx.doi.org/10.1016/j.cemconcomp.2015.10.018.

Yen, C.-L., Tseng, D.-H., Lin, T.-T., 2011. Characterization of eco-cement paste produced from waste sludges. Chemosphere 84, 220-226. http://dx.doi.org/ 10.1016/j.chemosphere.2011.04.050.

Zhang, L., 2013. Production of bricks from waste materials - a review. Constr. Build. Mater. 47, 643-655. http://dx.doi.org/10.1016/j.conbuildmat.2013.05.043.

Zhang, T., Gao, P., Gao, P., Wei, J., Yu, Q., 2013. Effectiveness of novel and traditional methods to incorporate industrial wastes in cementitious materials-an overview. Resour. Conserv. Recycl. 74, 134-143. http://dx.doi.org/10.1016 j.resconrec.2013.03.003. 